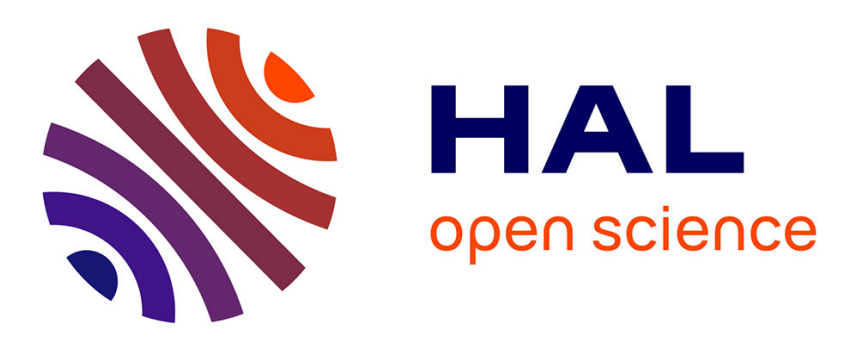

\title{
A Group Selection Perspective on Economic Behavior, Institutions and Organizations
}

\author{
Jeroen C.J.M. van den Bergh, John M. Gowdy
}

\section{To cite this version:}

Jeroen C.J.M. van den Bergh, John M. Gowdy. A Group Selection Perspective on Economic Behavior, Institutions and Organizations. Journal of Economic Behavior and Organization, 2009, 72 (1), pp.1. 10.1016/j.jebo.2009.04.017 . hal-00695532

\section{HAL Id: hal-00695532 \\ https://hal.science/hal-00695532}

Submitted on 9 May 2012

HAL is a multi-disciplinary open access archive for the deposit and dissemination of scientific research documents, whether they are published or not. The documents may come from teaching and research institutions in France or abroad, or from public or private research centers.
L'archive ouverte pluridisciplinaire HAL, est destinée au dépôt et à la diffusion de documents scientifiques de niveau recherche, publiés ou non, émanant des établissements d'enseignement et de recherche français ou étrangers, des laboratoires publics ou privés. 


\section{Accepted Manuscript}

Title: A Group Selection Perspective on Economic Behavior, Institutions and Organizations

Authors: Jeroen C.J.M. van den Bergh, John M. Gowdy

PII: $\quad$ S0167-2681(09)00125-5

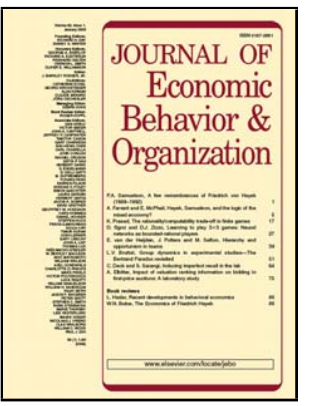

DOI: $\quad$ doi:10.1016/j.jebo.2009.04.017

Reference: $\quad$ JEBO 2384

To appear in: Journal of Economic Behavior \& Organization

Received date: $\quad 8-4-2008$

Revised date: $\quad 30-4-2009$

Accepted date: $\quad 30-4-2009$

Please cite this article as: van den Bergh, J.C.J.M., Gowdy, J.M., A Group Selection Perspective on Economic Behavior, Institutions and Organizations, Journal of Economic Behavior and Organization (2008), doi:10.1016/j.jebo.2009.04.017

This is a PDF file of an unedited manuscript that has been accepted for publication. As a service to our customers we are providing this early version of the manuscript. The manuscript will undergo copyediting, typesetting, and review of the resulting proof before it is published in its final form. Please note that during the production process errors may be discovered which could affect the content, and all legal disclaimers that apply to the journal pertain. 


\title{
A Group Selection Perspective on Economic Behavior, Institutions and Organizations
}

\author{
Jeroen C.J.M. van den Bergh* \\ ICREA Professor \\ Institute for Environmental Science and Technology \\ \& Department of Economics and Economic History \\ Autonomous University of Barcelona, \\ Edifici Cn - Campus UAB \\ 08193 Bellaterra (Cerdanyola), Spain \\ jeroen.bergh@uab.es \\ and \\ John M. Gowdy \\ Rittenhouse Professor of Humanities and Social Sciences \\ Department of Economics \\ Rensselaer Polytechnic Institute \\ Troy, NY 12180-3590, USA \\ johngowdy@earthlink.net
}

* Also Professor of Environmental and Resource Economics, Faculty of Economics and Business
Administration, and Institute for Environmental Studies, Vrije Universiteit, Amsterdam, The Netherlands.
Fellow of Tinbergen Institute and NAKE. 


\begin{abstract}
This article examines the role of group dynamics and interactions in explaining economic behavior and the evolution of institutions. Our starting point is the large literature on group selection in the biological, behavioral and social sciences. We present a range of interpretations of group selection, describe a complete set of group selection mechanisms, and discuss the empirical and experimental evidence for group selection. Unique features of cultural group selection are investigated, and opportunities for applying the latter to various areas of economic theory and economic policy are identified.
\end{abstract}

Keywords: altruism, altruistic punishment, assortment, downward causation, functionalism, group formation, multilevel selection, other-regarding preferences.

JEL code: B52; D02; D71.

Acknowledgements: We thank Julián García and three anonymous referees for useful comments. 


\section{Introduction}

Dominant theories in economics, including behavioral economics, are based upon selfreferential individual behavior and neglect the role of groups. As a result, such theories have an upward causation perspective. Here it is argued that inclusion of group level phenomena in economic analysis is relevant because the presence of groups can change the behavior of individuals as well as the interactions among them, and in turn may affect the economic system as a whole. The combination of individuals and groups means that upward and downward causation operate simultaneously. ${ }^{1}$

Our starting point is group selection theory in biology. It addresses the emergence, growth and selection of groups, including mergers, takeovers and conflicts between groups. It offers arguably the best available framework for thinking about group dynamics and the interface between individuals and groups. Various behavioral and social sciences have drawn upon the large and growing literature on group selection, which has given rise to the distinction between genetic and cultural group selection. This paper examines the application of group selection theory to economic behavior and institutions. Combining individual and group levels (or more precisely within-group and between-group processes) in a single analysis results in a multilevel approach, which is more complex than a system limited to upward causation of processes at the individual level. This additional complexity may partly explain why notions of multilevel and group selection have been surrounded by considerable debate.

Group processes often involve other-regarding decision-making, such as imitation, concern for relative position, and social rewards and punishment. Related theories of bounded rationality can be considered as complementary to theories of group processes. Recent theoretical and experimental findings indeed suggest that groups, norms and social context are essential to explanations of individual choice (Akerlof, 2007; Fehr and Fischbacher, 2002). However, the dynamics of, and interaction between, multiple groups is rarely considered in theoretical explanations of these empirical studies.

Including groups and their evolutionary dynamics in models of economic behavior and systems may enhance the study of a number of topics relevant to economics in four different ways. First, inclusion of groups can clarify the impact they have on cooperation, the structure of institutions, and conflicts over economic distribution. Second, it can help to design adequate institutions or public regulations for dealing with collective action dilemmas. Indeed, standard

\footnotetext{
${ }^{1}$ A group is a stable set of individuals having a closer connection (communication, cooperation, sharing, helping) with each other than with non-members. The group often is clearly demarcated from nonmembers in space, a network or time. A group can be defined as having characteristics that emerge from the interactions between individuals. Indicators of this can be average behavior, variance of behavior, group size, communication networks, group norms and rules (or more complex institutions), cooperation, internal labor division and other aspects of group organization. Firms can be considered as groups, but are in economics usually treated as analogous to individuals, certainly when described as part of a larger system (such as in a general equilibrium system).
} 
public policy solutions to common dilemma type problems are based on models assuming purely self-regarding preferences. Such policies may fail to address real world situations characterized by group norms influencing individual preferences and interactions (Bowles, 2008). Third, combining group and individual levels of description allows for the analysis of countervailing forces of within- and between-group processes. Finally, group evolution illuminates the complex organizational structure of human economies, involving nested structures, conflict between groups, and the coevolution of different sets of groups and individuals (Hannan and Freeman, 1977, 1989; Potts, 2000).

The combination of evolution and groups means a focus on ultimate, as opposed to proximate, explanations. This is increasingly accepted as the most suitable way to understand the fundamental nature, history and dynamics of complex systems. Of course, one can simplify and assume away dynamics or just pose mechanistic dynamics (i.e. absence of populations, diversity, innovation and selection) in any particular analysis, but only an encompassing evolutionary framework is able to clarify the margin of error and the conditional range of explanation resulting from such a simplification.

An important basis for thinking about groups is the recently revived debate on group selection in biology and the behavioral and social sciences (Bergstrom, 2002; Boyd and Richerson, 1990; Field 2001; Henrich, 2004; Sober and Wilson, 1998; Wilson and Hölldobler, 2005; Wilson and Wilson, 2007; van Veelen and Hopfensitz, 2007). Despite continuing disputes, the extensive literature on group selection is now an integral part of the large body of evolutionary thinking. ${ }^{2}$ It makes a subtle distinction between genetic and cultural group selection. This reflects the fact that that biological organisms (including humans) make use of all kinds of 'learning mechanisms', which can be broadly classified into genetic transmission and cultural transmission (with epi-genetic and phenotypic plasticity effects as either subcategories of these or additional categories). Gintis $(2007,5)$ refers to this as gene-culture coevolution.

Group selection has received little attention in economics. Rudiments of cultural group selection arguments were implicit in Hayek (1976 and later work). He argued that customs, morals, laws and other cultural artifacts are subject to group selection, generally surviving and replicated if they benefit survival and expansion of the human groups carrying them. ${ }^{3}$ Others have used the term group selection but with a very loose interpretation that does not always clearly separate between sociobiology-based kin selection and group selection applied to nonkin groups (e.g., Samuelson, 1993). They nevertheless seem to support the view that multilevel phenomena deserve more attention in economics, which is consistent with, though not identical

\footnotetext{
${ }^{2}$ It is surprising therefore that in a review of the biological basis of economic behavior Robson (2001, 2002) did not even mention group selection.

${ }^{3}$ For a critical perspective on Hayek's view see Steele (1987).
} 
to, the vision presented by Potts (2000), who regards economic systems as complex "hyperstructures" or nested sets of connections among components.

Parsimonious modeling, characteristic of both theoretical economics and theoretical biology, runs into problems when groups and resulting multilevel phenomena are added to the picture. Simple models are unable to adequately address group-related phenomena like synergetic interactions among individuals, relative welfare and status seeking, clustering of individuals due to spatial isolation, multilevel selection, and the combination of upward and downward causation (van den Bergh and Gowdy, 2003). Not surprisingly, one can find many different approaches to model group selection (Garcia and van den Bergh, 2007). It is likely that some of the results obtained with formal models in the 1960s and 1970s are not as general as once thought, because of the limitations of these models. Indeed, at the time, numerical analysis with complex, multilevel and spatial models was limited if not impossible.

In addition to evolutionary theories of group formation and selection, there exist a number of less well-defined theories about groups (e.g., Forsyth, 2006). These involve concepts like networks and hierarchies, and employ proximate explanations based on psychological, sociological, and economic reasoning. In addition, there are experimental studies which examine the effects of groups (see Section 4). In mainstream economics fundamental change at the level of groups or institutions is usually framed as a rational and deliberate choice among options, rather than an endogenous phenomenon as in evolutionary theories (van den Bergh and Stagl, 2003). For example, North's (1981) original view was that institutions are "chosen" based on efficiency, although later he changed this view dramatically (North, 1997). Institutional economics and related work in sociology employ a rich palette of in-depth, historical case studies of group phenomena which tend to be more descriptive than analytical and predictive (van den Bergh and Stagl, 2003). We believe that evolutionary explanations based on withinand between-group selection can offer more fundamental explanations.

In this paper we show the value of genetic and cultural group selection theory as applied to economics. Both genetic and cultural group selection have influenced human nature and culture, although cultural group selection is arguably most relevant to current and future socialeconomic phenomena. Two notable papers on group selection have been published in economic journals, namely Bergstrom (2002) and Henrich (2004). The first of these offered a clear exposition of a selected number of formal group selection models, while the second gave an impressive and complete (and quite complementary) account of group selection. Other "economic papers" on group selection and economics (Bergstrom, 2002; Bowles et al., 2003; Choi and Bowles, 2007; Field, 2001, 2008; van Veelen and Hopfensitz, 2007) present a more limited approach focusing on specific issues and applications. The remainder of our paper is organized as follows: 
Section 2 presents a set of alternative definitions and interpretations of group selection, preparing the reader for possible confusion about group selection. Section 3 discusses notions and theories in biology competing with or otherwise related to group selection, and along the way clarifies a number of features of group selection. Among other things, we have tried to provide a fair representation and evaluation of the central debate on kin versus group selection. Section 4 is an account of the experimental and empirical evidence for (genetic and cultural) group selection, within both the natural and social sciences. Section 5 offers a systematic account of the mechanisms through which genetic group selection can operate. Section 6 identifies unique features of cultural group selection as distinguished from genetic group selection. Section 7 sketches the implications of (mainly cultural) group selection for various areas of theoretical, applied and policy analysis in economics. Section 8 concludes.

\section{What is group selection?}

To understand the debate on (genetic and cultural) group selection one has to first understand the many definitions and interpretations of the phenomenon (Bergstrom, 2002; Field, 2003a, b; Gintis, 2000; Henrich, 2004; Sober, 1981; Sober and Wilson, 1998; Soltis et al., 1995; Wilson (D.S.), 1975, 2002; Wilson and Sober, 1994):

- Differential survival and reproduction of groups within a population. Dysfunctional (nonadapted) groups become extinct and are replaced by relatively successful (well-adapted) groups. Here adaptation is to a given environment in which the population resides. Such a group evolution process requires a diversity of groups, in terms of composition of individuals, genes or strategies or institutions. (This will serve as our working definition here.)

- The frequency of genes (or more precisely alleles) is affected by the benefits and costs they bestow on groups.

- The fitness of every member of a group depends on a common characteristic not isolated in an individual. This may be a social institution ('group meme'). Examples of these are more evident in a socio-economic than in a purely biological realm, so that this interpretation perhaps better fits cultural rather than genetic group selection.

- The fitness of every member of a group depends on the behavior of the other individuals in the group. In genetic group selection this is made explicit through non-additive genetic interaction occurring between individuals within a group (e.g., with regard to altruism or aggression).

- Evolution is combined with functionalism. Group functionality means that 'the whole is greater than the sum of its parts'. A particular example in biology is regarding groups as superorganisms, as has been common in the case of colonies of social insects (Wilson and Hölldobler, 2005). Wilson (2000) refers to this as group-level functionalism. The 
combination of group evolution and functionalism goes beyond traditional thinking in terms of functionalism - notably in sociology - as the latter lacked a dynamic context in terms of explaining the mechanisms that give rise to and alter group-level or social functions. Functions of groups co-determine fitness and thus sensitivity to selection pressure.

- Groups function as adaptive units. Group adaptation is realized or improved through evolution (diversity and selection) at the level of groups.

The many interpretations of group selection in the literature suggest that the concept has many facets and that different authors are not always addressing exactly the same phenomenon. Different authors stress different core mechanisms of group selection (see Section 5). In addition, while the number of articles providing theoretical arguments, formal models, empirical regularities and experimental findings in support of group selection is steadily growing, several respected biologists still see fundamental problems with (especially genetic) group selection. Others consider it to be theoretically possible but rare and quite unimportant. All this suggests that the debate on group selection has not yet converged into a single, agreed-upon theory. Yet it is clear that the concept of group selection is now more broadly supported within biology than a few decades ago. For example, in an important turnaround, the eminent biologist E.O. Wilson now takes the position that genetic group selection acted as the strong binding force in eusocial evolution, and that close kinship is likely to be a consequence of eusociality rather than a critical factor in its evolution (Wilson and Hölldobler, 2005; Wilson and Wilson, 2007).

Group selection is often discussed and judged in terms of its application to altruism. However, group phenomena can be linked to a variety of social (other-regarding) preferences including reciprocity, reciprocal fairness, inequity aversion, pure altruism, altruistic punishment, spite, envy and status-seeking (comparison). Second, group selection can address a range of genetic or individual interactions, notably cannibalism (especially insects), conflict (fighting) and complementary roles (labor division) such as in community selection (Goodnight and Stevens, 1997; Swenson et al., 2000). So any genetic or cultural trait might influence within and between-group selection, even if the directions of the effects of these are not necessarily opposite as in the case of altruism.

\section{What economists can learn from the group selection debate}

Natural selection above the level of the individual was a quite acceptable idea to Darwin, Wallace and Spencer, all of whom believed in the differential survival of groups. Nevertheless, group selection was originally met with skepticism if not outright hostility, partly due to the publication of Wynne-Edwards (1962) book Animal Dispersion in Relation to Social Behavior, which was later evaluated as an incorrect statement of group selection and inconsistent with 
modern formulations of it (Wilson, 1983). ${ }^{4}$ Wynne-Edwards received strong adverse reactions from authorities in biology, notably Williams (1966). Two widely accepted theories countered Wynne-Edward's version of group selection. One was kin selection, the idea that apparent altruism is genetically based because altruists are actually protecting their own genes (inclusive fitness) by helping close relatives survive (Hamilton, 1964). The other was reciprocal altruism, the view that apparent altruism was based on the expectation that favors would be returned (Trivers, 1971). These two theories formed the basis of a new field, 'sociobiology', which initially was opposed to the idea of group selection, arguing that social behavior is entirely the result of gene-level and individual-level selection (Ruse, 1979;.Wilson, (E.O.), 1975).

While the critique of Wynne-Edwards's version of group selection was correct, it should not be misinterpreted as undercutting later, more sophisticated, conceptualizations of group selection. Williams' influential critique contained many misperceptions of group selection, one being the averaging fallacy. This means that group selection effects are attributed to individuallevel (i.e. between-individual) selection due to simply calculating the average fitness of individuals across groups, rather than decomposing it into average fitness per group and a between-group selection component depending on the relative size of groups in the total population (Wilson, 1983). The averaging fallacy in fact merely defined group selection away, rather than showing it to be incorrect.

Williams assumed that when a trait is decreasing in frequency in every group, its population frequency must also decrease. Surprisingly, this is not necessarily true. The reason is differential growth at the group level which causes the composition of the population in terms of relative group sizes to change. The net outcome may be that the trait will increase in frequency in the overall population. In statistics this is known as Simpson's (1951) paradox. Suppose a population consists of two groups, then this paradox requires that the group with relatively many individuals with the trait grows relatively fast compared to the groups with relatively few individuals with the trait; the proportion in the population of the first group will then increase (note that this is a necessary but not sufficient condition). In mathematical terms this can be formulated as follows. Suppose that population size at time $t$ is $p(t)$, the population consists of two groups with sizes $g_{1}(t)$ and $g_{2}(t)$, the number of individuals with the trait is $a(t)$, and $a_{i}(t)$ in group $g_{i}(t)(i=1,2)$. Then $p(t)=g_{1}(t)+g_{2}(t)$. Now even if the changes over time in frequencies of the trait are characterized for group 1 by $a_{1}(t+1) / g_{1}(t+1)<a_{1}(t) / g_{1}(t)$ and for group 2 by $a_{2}(t+1) / g_{2}(t+1)<a_{2}(t) / g_{2}(t)$, then it is still possible that the trait's frequency in the population increases: that is, $\left[a_{1}(t+1)+a_{2}(t+1)\right] /\left[g_{1}(t+1)+g_{2}(t+1)\right]>\left[a_{1}(t)+a_{2}(t)\right] /\left[g_{1}(t)+g_{2}(t)\right]$ or

\footnotetext{
${ }^{4}$ Wilson and Sober (1994) make a distinction between naïve and modern group selection theories. Wynne-Edwards (1962) is considered an example of the first as his theory does not account for effects of individual selection and essentially assumes that higher level adaptation (even of a single, isolated group) is a fact. Modern group (or multilevel) selection theory instead recognizes simultaneous processes of individual and group selection, as well as group selection requiring multiple groups.
} 
$a(t+1) / p(t+1)>a(t) / p(t)$ holds. To illustrate the numerical possibility: $1 / 4<2 / 7$ and $5 / 7<3 / 4$ while $(1+5) /(4+7)=6 / 11>5 / 11=(2+3) /(7+4)$. The example suggests that a rather special case is required, which is not surprising, otherwise it would not have been called a paradox. The paradox just shows the power of group selection, that in principle it can increase a trait's frequency in a population even if its frequency falls in all groups. The net effects of group selection can be much larger if the frequency of traits can also increase in certain groups. The latter is the more common or general case of group selection, as will become clear later.

Especially in the context of altruism, the relationship between kin and group selection has been subject to much debate. First, the observed presence of high kin relatedness in a population should not be confused, as is often done, with kin selection acting as a crucial factor in the historical evolution toward the current system (Griffin and West, 2002). In the context of eusociality, it is now considered likely that group selection gave rise to kin selection which in turn produced a high degree of relatedness in colonies (Wilson and Hölldobler, 2005). Indeed, repeated group selection may increase relatedness in a group, through limited dispersal or inbreeding (Hamilton, 1975), thus providing a basis for more effective kin selection. Things get even more complex when group and kin selection function in tandem (Aviles et al., 2004). It is also often overlooked that the effect of kin selection, such as altruism benefits to kin and thus selfish benefits from the shared gene's perspective, is opposed by competition between kin (Frank, 1998). Of course, seemingly altruistic behavior among kin-related individuals can simply be the result of direct, reciprocal or general group (i.e. not kin-group specific) benefits (Griffin and West, 2002).

It has been suggested that kin and (certain types of) group selection are conceptually or mathematically equivalent. Some have argued that kin selection is a subset of group selection, namely when group members are close kin. Indeed, the more general model seems to be group selection occurring through assortment (association or clustering of related traits or strategies), while kin relatedness can be seen as a special case of such assortment, namely of genetically similar individuals. This does, however, not clarify whether group selection is more or less useful as a formalized approach to study reality. Possibly, if kin selection is generalized as inclusive fitness theory where inclusiveness applies to assorted individuals (or genes), then group selection might be (seen as) a special case of it (Grafen, 2007). Foster et al. (2005) stress that kin selection does not require family relatedness caused by (recent) common ancestry, but only genetic correlation among individuals (including among loci). This seems to come down to the same generalized inclusive fitness based on assortment. By stretching the meaning of kin selection so much, group and kin selection may indeed coincide. 
Virtually all authors debating this point assume that group selection always involves assortment, and many think that such assortment is only kin based. ${ }^{5}$ However, group selection can operate through other channels than assortment and inclusive fitness. Van Veelen and Hopfensitz (2007) and van Veelen (2008) emphasize as an important alternative mechanism a shared interest or fate of group members (see Section 5). So the equivalence may hold, but only for a subset of group selection models, namely those in which assortative group formation is the key mechanism. The model-based literature shows that formalization of groups generally results in quite different mathematical formulations than those based on of kin selection, and they are not necessarily reducible to one another. Moreover, they may employ different types of specific assumptions and as a result they can differ in accuracy of describing organisms and their evolution (Queller, 1992). Nevertheless, the similarity between Hamilton's rule and rules arising from group selection has been shown for certain types of group selection models (e.g., Frank, 1997; Grafen, 2007; Lehmann et al., 2007, Ohtsuki et al., 2006). The distinction in practice between group and kin selection as a causal mechanism may ultimately depend on the type of data gathered, as has been argued by various authors (Colwell, 1981; Griffin and West, 2002).

Wilson (1983) notes that whereas kin selection emphasizes inclusive fitness and the impact of altruism on other individuals, group selection emphasizes relative fitness in groups and impact of altruism on the (relative) productivity of the group. They are different ways to understand processes that are similar when groups are defined as consisting of close kin. Moreover, group selection can operate when group members are not each other's kin. Kin selection has also been invoked to explain altruistic acts, in this case among strangers in large human groups. The reasoning is that since humans evolved in groups with close kin relationships they are accustomed (programmed) to act to a certain degree altruistically. Moreover, people are supposed to possess an imperfect psychological capacity to distinguish kin from non-kin, or altruists from defectors. Such kin-type of behavior is easily extended to non-kin in larger groups in modern societies. Henrich (2004), however, provides several empirical arguments against this reasoning: individuals clearly distinguish between close from distant relatives, have frequent encounters with strangers, and do not cooperate to the same degree with all group members.

Reciprocal altruism refers to behavior based on the expectation that favors will be returned. This requires a certain minimum level of cognition. Reciprocal interaction has been invoked to explain altruistic acts toward strangers. The main problem raised by this is that reciprocity requires repeated interaction or trust that an altruistic act will be reciprocated.

\footnotetext{
${ }^{5}$ Grafen (1984, p.83) states that group selection theory is worthwhile if genetic similarity is the result of kinship and if populations have a clear group structure. But then group selection will immediately come down to inclusive fitness calculation. About "preferential assortment" he (p. 79) suggests that "... the only plausible cause of genetic similarity among group members is common ancestry..." because "It is unlikely that the locus for altruism is closely linked to the loci for habitat preference."
} 
However, if individuals are strangers neither condition is satisfied. The more credible explanation for generalized reciprocity as the basis of altruism in large groups is that it is an extension of evolved reciprocity in small groups consisting of individuals familiar with each other. Extended or indirect reciprocity, based on information of previous interactions with others, reflected in judgment of reputation and morality and involving trust, is apparently present in some animal as well as human societies. In humans it has led to complex social interactions with correlated demands on individual cognitive capacities (Nowak and Sigmund, 2005). Indirect reciprocity, however, can not serve as an ultimate explanation of human prosocial behavior, as this requires the "big mistake" hypothesis, which says that humans cannot differentiate between acquaintances and strangers, or at least do not treat them differently. But this hypothesis is refuted by various experiments (Henrich, 2004). This does not deny that both experimental and empirical studies indicate that individuals show altruism towards strangers in one-shot games (Fehr and Gachter, 2002). In addition, it should be noted that indirect reciprocity cannot solve the n-person dilemma (note that most published models are 2 person models). The reason is that it gives rise to multiple stable equilibria (Panchanthan and Boyd, 2005), so that it requires an equilibrium selection mechanism (with group selection as one candidate). In other words, group selection and indirect reciprocity are not alternatives (Henrich et al., 2006; Henrich and Henrich, 2007).

According to the biologist Alexander (1987), the evolution of ethics received a major stimulus from the long history of violent interactions among ancestral primate groups, and in line with this was aimed at strengthening the structure of the own group. This is supported by asymmetric behavior in conflicts among (living) apes and monkeys: conflict resolving inside the group, and extreme brutality to outsiders. Similarly, humans apply ethics asymmetrically to insiders and outsiders of the group they belong to. The most convincing examples of this are wars and religious and ethnic conflicts (de Waal, 1996, 29; Wilson, 2002). In a recent study, Choi and Bowles (2007) invoke a group selection model to show that group conflict between humans may be closely related to the evolution of parochial altruism (see also Garcia and van den Bergh, 2008). The latter has two faces, namely providing benefits to fellow group members and showing hostility towards outsiders, both at a personal cost. Field $(2008,210)$ phrases it as: "I acknowledge that our ability to make common cause has a dark side: the control of within group conflict sometimes lays the foundation for violent attacks on outgroups. But the inclination is also what brings millions of people to the polls in democratic nations and is as much an underpinning of democracy as it is of dictatorship".

Group competition and selection, together with reciprocal altruism, are considered by de Waal to be the set of essential building blocks of the evolution of morality. On a psychological level, the crucial change and stepping stone from non-moral animals to moral humans is the evolution of perceptions and empathy, that is, the ability to be affected by feelings 
of another organism or the situation in which it finds itself (more basic and neutral than sympathy). Empathy goes along with self-awareness, i.e. distinguishing oneself clearly from the environment or the rest of the world, and with perception, i.e. positioning oneself in different roles or individuals to understand a situation or problem. These lead to the moral community, in which not only direct, one-to-one interactions occur among individuals but also indirect ones: care about good relationships between others, and mediation and arbitration in conflicts. De Waal $(1996,34)$ calls this "community concern". Humans add to these mechanisms of punishment and reward explicitly focused at maintaining or improving the social environment, sometimes referred to as meta-norms (see Axelrod, 1986). Altruistic punishment leads to internalization of norms and rules and guilt-like behavior, common in humans and other primates, as well as in dogs. For the cases of group selection where empathy is involved, a minimum level of intelligence of individuals may be required. On the other hand, stable norms exist that reflect a complete lack of empathy (let alone sympathy), such as female circumcision in various human cultures and religions.

Wilson (2005) regards the distinction between absolute and relative fitness as essential to understanding the impact of group selection. By increasing the absolute fitness of individuals within a single, isolated group (or population) to the same degree, their relative fitness does not alter, so that the fitness change will be without evolutionary consequences. But when adding other groups that interact (perhaps depending on the same scarce resources), the absolute change in fitness for the original individuals will mean an improved average fitness of the group relative to that of other groups. Then the group may grow more quickly than other groups and thus will increase its proportion in the total population. The effect of this is only interesting if fitness differences between groups relate to diversity in the structural (genetic or cultural) basis of groups (i.e. their individuals). Wilson notes that explanations based on individual-level selection tend to neglect the possibility of group selection effects because they focus on absolute instead of relative fitness improvements. He notes that by changing strategy individuals may reduce their relative fitness even if they improve their absolute fitness, simply because the group as a whole benefits from their change of strategy, as in the case of altruistic acts. The problem is that the identification of individual-level selection with absolute fitness improvement frustrates the search for decomposing evolutionary change into within- and between-group selection contributions. At a more general level, using the wrong indicators may obscure satisfactory explanations of complex phenomena.

The most common argument against group selection is free rider behavior. The idea is that free riders will profit from the benefits of being part of a group with genuine altruism and social institutions, without contributing to these or contributing less than average. As the relative proportion of free riders in the group increases, the benefits for the group will slowly disappear. Moreover, it is relatively easy to be altruistic when resource scarcity and competition 
are low, but selection pressure is then quite low as well, so that this altruistic behavior will not quickly diffuse. On the other hand, altruism and altruistic punishment are less common when scarcity and competition are high, that is, when altruism implies a serious sacrifice. Because selective pressure is higher in the second case, individual-level selection will generally have a relatively larger impact. A major shortcoming of this reasoning is that it employs a single level explanation that excludes group variation and group selection. The latter allows groups with relatively many altruists to grow faster than other groups, as a result of which the proportion of altruists in the population as a whole may increase. This is the above mentioned Simpson's paradox. Moreover, group rewards to altruistic punishment are higher when resources are scarce. In addition, the reasoning is restricted to altruism and free riding, whereas group selection has a broader significance.

The conclusion is that evolutionary dynamics may be seen as resulting from a combination of within- and between-group selection, irrespective of how weak each force is in a species, system or certain period of time. This insight was formalized in the well-known Price $(1970,1972)$ equation which allows a decomposition of evolutionary changes into betweengroup and within-group effects. ${ }^{6}$ This should, however, not be considered as proof of the theoretical possibility or empirical effectiveness of group selection in real world contexts. ${ }^{7}$ Henrich (2004) uses the Price equation to derive a set of necessary conditions for group selection to be effective. Ceteris paribus, the larger the variation between groups, the more opportunity for between-group selection to be effective and dominate the within-group selection effects. Variation between groups is nevertheless hampered by migration, mixing and reformation of groups, which will receive attention later on.

\section{Experimental and empirical evidence for biological and cultural group selection}

Evidence for group selection comes from various sources. It comes from "artificial" selection in experiments and empirically-oriented studies using adaptationist analysis, as well as selection in non-human nature (animals, plants, communities and ecosystems) and in humans.

\footnotetext{
${ }^{6}$ A version of the Price equation was published more than fifty years ago by Crow (1955) as a multi-level extension of Fisher's Fundamental Theorem of Natural Selection. In an interesting commentary on the Price equation Crow (2004) points out that the first person to use covariances rather than variances was Robertson (1966) who extended Fisher's Theorem to traits other than fitness. According to Crow (2004) "Put these two together and you have Price's equation."

${ }^{7}$ The generality of the Price decomposition is further supported by the fact that Hamilton (1975) used it to reformulate his theory of inclusive fitness in group selection terms. This led him to conclude that the inclusive fitness approach to social behavior is more general than group selection, as the latter depends on a group structure whereas the first can also address ungrouped populations. Generality in this sense, however, does not mean that group selection is not useful or cannot generate additional, unique insights. Moreover, as previously discussed in this section, such a generalization applies only to one type of group selection, which functions mainly through assortment.
} 
Based on various experimental studies, Goodnight and Stevens $(1997,62)$ conclude that genetic group selection can be very effective in influencing genetic and phenotypic change over time. They find that group selection differs from individual-level selection in that it can influence interactions between individuals that are neglected in models only describing individual-level selection as well as in experiments allowing only for artificial individual-level selection. In defense of this statement they refer to 11 experimental studies between 1977 and 1996, on beetles (various cases), domestic rat (group selection through male cooperation in mating), plants (leaf area), and chicken (interaction between egg production and aggression).

Wade (1976) undertook experiments with beetles (Tribolium castaneum) and found significant group selection effects. Selection in these experiments focused on size of groups and was artificial. In only a few generations the group selection effects were very evident. In this case the concrete influence was altered rates of cannibalism. Wilson (1983), evaluating these experiments, notes that group size regulation can occur by cannibalism (selfish behavior) and voluntary birth control (altruistic). He argues that if selfish and altruistic strategies are both present, then group selection will foster the selfish strategy. This is surprising and contrasts with most of the literature critical of group selection, since it is almost taken for granted here that selfish strategies do not require group selection. Instead, it is generally believed that group selection only may need to be invoked to explain widespread altruism.

A surprising experimental finding is the group selection effects assessed in experiments with chicken egg production. Whereas artificial individual-level selection may maximize egg production for isolated chickens, group selection arranges a trade-off between productivity and aggression, which is relevant if chickens are to be housed in multiple-hen cages ("egg factories") characterized by aggressive interaction. Group selection realized a $160 \%$ increase in group yield or group-average egg production versus unselected controls, and likewise less aggression. The economic value of this result is evident: not only more egg production but also reduced hen mortality and less need for beak trimming (Muir, 1996).

The impact of group selection on plants is also surprising. Experimental results for groups covering low and high leaf area showed between-group selection to be more effective than between-individual selection (Goodnight and Stevens, 1997). Group selection theory has even been shown to apply to communities, i.e. involving interactions between individuals or populations of multiple species, resulting in community or ecosystem selection theory. This has also been confirmed by experiments (Goodnight, 1990a 1990b, 2000; Goodnight and Stevens, 1997; Swenson et al., 2000).

A necessary proviso of experimental findings supporting the potential effectiveness of group selection is that the artificial nature of selection likely means that effects will generally be stronger than when occurring under natural conditions. The more so since many experiments 
employ the propagule model (see Section 5). Nevertheless, the experiments support the direction and potential effectiveness of group selection as an evolutionary force.

To obtain a more complete picture other evidence is relevant. Empirically-oriented studies using adaptationist analysis are reported by Wilson (1983). He mentions a commonly cited example of group selection, namely the evolution of avirulence in a myxoma virus that was introduced into Australia to control the European rabbit. Each rabbit is a deme from the standpoint of the virus, so that the structured deme model of group selection can be applied. When a rabbit dies the associated virus group becomes extinct, as the virus cannot survive in a dead rabbit and mosquitoes necessary for diffusion do not bite dead rabbits. The virus groups that are alive are the least virulent. Therefore, even though avirulence has no selective advantage within a virus group, it arises through deme or group selection.

Goodnight and Stevens (1997) summarize field studies of group selection under natural conditions. They list five studies between 1989 and 1996, all of which supported the effectiveness of group selection. The studies deal with a number of traits and species, namely cannibalism in beetles, survivorship, flower production and fruit production in plants, and reproductive and worker allocation in ants. Some of these studies use 'contextual analysis' based on traits like population density and percentage ground cover, and group fitness indicators such as mean leaf area, mean plant height, and mean photosynthetic rate.

Another example of group selection under natural conditions often mentioned in the literature is biased sex ratios. Williams (1966) showed that under certain assumptions individual-level selection would give rise to an even sex ratio while group selection would lead to a female-biased sex ratio. The absence of such biased sex ratios in nature he regarded as evidence against group selection. However, later female-biased sex ratios have been assessed in hundreds of species, which is a very possible result of equilibrium between opposing forces of within- and between-group selection (Colwell, 1981; Frank, 1986).

With regard to social insects, Wilson and Hölldobler (2005) argue that genetic group selection needs to be invoked to offer a complete explanation of the evolution of eusociality. They regard close kinship likely to be a consequence of eusociality rather than a critical factor in its evolution. They think that only group selection is able to provide a consistent explanation for two central empirical facts: the rareness of eusociality and the ecological dominance of eusocial insects over solitary and pre-eusocial competitors. In particular, evolution of eusociality had to involve two phases of group selection: initially competition between solitary individuals and cooperative pre-eusocial groups, and later on competition between colonies, groups with strong cooperation and close genetic relatedness. Group selection is able to counter the dissolutive effects of selfish individual behavior, giving a chance for kin selection to emerge. Comparison of the history of insects with and without eusociality yields some insights about preconditions for eusociality to evolve, namely individual preadaptations such as building 
nests and feeding larvae, both of which foster cooperation within groups. Moreover, the key adaptation of eusocial species is defense against all sorts of enemies in which groups are better than individuals (Wilson and Hölldobler, 2007). It is long established that more advanced eusocial species are characterized by more labor division and subtle, chemical communication, which makes groups function more effectively in reproduction, conflicts and foraging.

Support for genetic and cultural group selection in humans evidently cannot make use of artificial experiments. Instead, evidence here takes a more indirect form, as discussed in Boyd et al. (2003) and Henrich (2004). Wilson's (2002) group-selection explanation of religions offers one of the best arguments for the relevance of cultural group selection for the social sciences. He shows that there always has been a large diversity of religions, that religious groups are quite stable (existing for many human generations), that they compete and enter in violent conflicts (even within single 'meta-religions' like Christianity and Islam), that they bind groups very strongly through fear and punishment, and that they reproduce very well (propagation mechanisms include indoctrination of children, rules about partners and offspring, and active efforts to convert non-believers). Moreover, the suggestion that the most powerful and impressive god is a solitary god may have helped monotheist religions to become dominant in the world. Note that the evolution of religions is relevant to economics, as religions provide institutions and rules with important economic repercussions (Iannaccone, 1999). Landa (2008) generalizes the idea of selection of religious groups to "homogeneous middleman groups" supported by many historical examples of merchants/traders.

With regard to non-religious institutions, Gürerk et al. (2006) show experimentally that a sanctioning institution comes out as the winner when competing with a sanction-free institution. In Gürerk et al.'s experiments, despite initial aversion, the entire population ultimately chooses the sanctioning institution. This indicates the relevance of institutional selection for collective action.

The evidence coming from primate research is mixed. Some of it underpins the relevance of groups in behavior and evolution. Silk et al. (2003) show that infants of more social female baboons have a greater chance of surviving to the first birthday. Melis et al. (2006) find that chimpanzees recognize when collaboration is useful or necessary and know how to select among non-kin the best collaborative partners. These authors argue that since such skills are shared with humans, they may have characterized a common ancestor. However, in several chimpanzee experiments chimps act like Homo economicus (Silk et al., 2005). In addition, de Waal $(2006,16)$ notes that in primate species males or females often leave the group and join neighboring groups. This suggests genetic isolation is imperfect and group selection effects are weakened. One should be careful, however, not to jump to the conclusion that such effects are entirely absent, as genetic differences between groups will not necessarily disappear completely. 
Many reputable biologists have expressed the view that genetic and cultural group selection has likely played a role in the evolution of humans, even if they question the relevance for animals (plants are surprisingly neglected). In addition, indirect experimental evidence is available. In psychology group experiments have been performed and contrasted with similar experiments with isolated individuals (Bornstein and Ben-Yossef, 1994). Although not strictly about evolution, these studies make clear that interactions between individuals affect individual strategies. Competition among groups turns out to be of influence on group outcomes. Even the awareness of another group makes a difference in terms of individual play. Because of a lack of space, we abstain from mentioning further examples from psychology that indirectly support the relevance of group selection.

In spite of the documented experimental and empirical evidence, one may wonder why attribution of experimental or empirical findings to group selection is still rare compared to individual-level selection. Wilson (2005) convincingly argues that this is largely due to ignoring the difference between absolute and relative fitness (Section 3). Typically, researchers do not distinguish between group and individual-level selection effects on fitness but immediately calculate net effects and then automatically attributes these to individual-level selection.

\section{Mechanisms of group selection}

In this section we provide a set of mechanisms of genetic group selection. As some of these also apply to cultural group selection, understanding them can clarify how group selection might function in economic settings. Some of the mechanisms are necessary for group selection to occur while others merely make it more likely or more effective. Not surprisingly, the lack of attention to important factors in early analyses explains why past researchers have often dismissed the possibility or effectiveness of group selection. The following factors are considered here: (1) migrant pool versus so-called propagule type of population dynamics (relating to group formation), (2) (non-random) assortment, (3) (1) type of population structure (spatial, behavioral), (5) institutions, (6) splitting of groups, (7) group conflict, and (8) nonadditive (genetic) interaction between individuals. Some of these factors have received more attention in modeling than others. No model captures all of them, so that there really is no general or complete model of group selection. In fact, a systematic combination of all possible assumptions relating to these factors is missing in the literature on formal modeling of group selection (Garcia and van den Bergh, 2007).

Whereas individuals are concrete, stable entities, groups are more vague and fluid, which raises the question of how groups come into existence. Groups can originate through random isolation, inbreeding, ecological specialization or non-random assorting. Slatkin and Wade (1978) noted two alternative approaches to describe the colonization of areas (habitats) referred to as migrant pool and propagule models. In the migrant pool model all populations 
contribute migrants to a common pool from which colonists are drawn at random to occupy areas, so that there is complete mixing of individuals from different populations. The haystack model by Maynard Smith (1964) is a well-known example. In the propagule model a pool is made up of individuals derived from a single population so that there is no mixing of individuals from different populations. Through cumulative mutations in, and selection of, genetic or cultural characteristics, much more among-group diversity can be realized, and in turn group selection can be much more effective. Seen another way, in comparison with the propagule approach, the migrant pool model means that something which might be termed 'group heritability' or group reproduction - a core element of any evolutionary system - is largely absent, suggesting that group evolution will be incomplete and thus ineffective or even nonexistent. However, this may not be the case if group conflict is introduced (see below). Finally, repeated group selection in a propagule type framework with isolated small groups sensitive to drift can produce increasing kin relatedness and ultimately give rise to speciation. ${ }^{8}$

An important cause of group formation and selection is non-random, assortative interaction, which can be opposed to randomly remixing groups. Special cases are preferential assorting and common ancestry (kin selection). Assortative interactions lead to nonrandom variation among groups. This mechanism is operative, for instance, if altruists are able to recognize other altruists. This works in any case within the context of extended families and small groups, and for larger groups if individuals satisfy a minimal degree of cognitive abilities or (social) intelligence in combination with experience (learning). Random variation in small groups can produce outcomes that resemble non-random assorting, which is often referred to as genetic or cultural drift. Assorting can also occur through kin-recognition resulting in extended family groups, in which case group selection is equivalent to kin selection (Hamilton, 1964). In biological contexts inbreeding is an important case of assortative grouping according to kin features. Other results can be obtained for different assorting rules. Bergstrom (2003) offers a generalized account based on an "index of assortativity". He explains the evolution of cooperation under assorting as the cost of cooperating being compensated by higher probabilities and associated higher benefits of meeting a cooperating partner. In an economic context assortative grouping will depend on group-specific institutions that promote cooperation and altruism, such as education, religion, political voting systems and free press.

\footnotetext{
${ }^{8}$ Traulsen and Nowak (2006) provide a model of group splitting. It allows only for interaction between individuals within strictly separated groups. Groups split endogenously when (successful) groups reach a certain maximum size, while another group is eliminated so as to keep the total number of groups constant. This can be seen as a special type of propagule pool model. It is applied to prisoners dilemma games between cooperators and defectors, and a fundamental condition for the evolution of cooperation is $b / c>1+n / m$, with $b$ and $c$ denoting the benefit and cost of an altruistic or cooperative act, respectively, and $n$ and $m$ the maximum group size (where probabilistically splitting occurs) and the number of groups. With smaller maximum group size or with more groups, the condition is more easily satisfied and cooperation is favored by multilevel selection. A modified formula is derived for the case including migration, which weakens the effect of group selection.
} 
Assortative interaction depends on the effectiveness with which individuals recognize others with similar characteristics. This problem is often formalized through signaling games. In a biological sense this can depend on chemical signals (kin selection - e.g., ants). In a cultural setting it can involve location of meeting (public space - bar, political party), expression of ones convictions (verbally, through physical appearance - e.g., clothing style). In order to be stable, this requires a constraint on, or complete lack of, mutations. The 'green beard effect' as a special case of 'signalling' is relevant here (Dawkins, 1976; Henrich, 2004). Suppose altruists have green beards which allow them to recognize and cooperate with each other; but due to mutation selfish individuals also start to grow green beards. The result is a steady increase of the proportion of selfish individuals in the population. This is a special case of free riding behavior as discussed earlier, but based on reaction to signals. The effectiveness of assortative grouping in creating a sustainable 'altruistic group' depends on the relative forces of assortative interaction and mutations in defectors that allow them to send out fake signals. If the first dominates, altruism can survive; if the second dominates, altruistic behavior is unsustainable and driven out by selfishness. In general, altruism can be sustained only if signaling and assorting is cheaper for altruists than is faking the signal for selfish individuals (Henrich, 2004).

Pepper and Smuts $(2000,2002)$ argue that the existence of spatial or patchy environments provides a sufficient basis for group selection, and that there is no need for ex ante, stable discrete groups. They also present an explicitly spatial model in which nonrandom assortment occurs through individuals reacting to local environments by migrating in such a way that those with similar traits end up relatively more abundant in a new locality. The result is that environments are positively correlated with individual traits. Environmental change, such as environmental degradation or increasing resource scarcity, may induce individual responses that stimulate assortment. Pepper and Smuts work can be linked to the growing literature on local interaction evolutionary (multi-agent) models. Here agents perceive costs or benefits that depend on strategies by other agents in their immediate environment. For example, punishing or being punished can both be associated with a cost that depends on how many defectors or enforcers exist in the local environment of an agent (Bergstrom and Stark, 2003; Eshel et al., 1998, 1999; Nowak and Sigmund, 2000). These studies illustrate the general case that a change at a higher level (a group) alters the rules (cost and benefits, or fitness logic) at the lower level of individual agents. In such models the survival of a certain agent or strategy depends on the local population environment, which can be interpreted as a case of the general intrademic or trait group selection model. Trait here refers to features of individuals affecting the fitness of other individuals in the group (genetic interaction). Eshel et al. (1998) show that in a world with local interactions between altruists and egoists, altruism is a strictly dominated strategy, but altruists can survive as long as they are grouped together and push up each others performance. For example, Noailly et al. (2009) show that local equilibria consist of a protection layer of 
enforcers. In view of the foregoing it is surprising that the literature on local interactions with evolutionary agent-based modeling does not make reference to group selection. Integrating these literatures offers a fruitful research direction.

The traditional method to study these issues, systems of dynamic equations such as theoretical population models and evolutionary game theory, cannot address multilevel selection based on local interactions and spatial heterogeneity of environment and populations (Pepper and Smuts, 2000). The traditional theoretical approach makes simplifying assumptions, consistent with the principle of parsimony (Williams, 1966), which may be wholly unsuitable for the analysis of group selection. Possible oversimplifying assumptions include homogenous populations, fixed split-up of groups and infinite population sizes. Most fundamental is that the groups are exogenous and fixed, whereas in more realistic spatial, local-interaction or agentbased evolutionary models groups are endogenous while boundaries between groups change. The neglect of these features partly explains why many theoreticians in biology have insufficiently recognized the relevance of group selection. This is all the more surprising given that the crucial role of space for speciation was clearly recognized by the founders of modern evolutionary biology, Darwin and Wallace, and was elaborated in the theory of island biogeography (MacArthur and Wilson, 1967).

Bowles and Gintis (1998) regard the spatial dimension as important to address four mechanisms employed by communities to solve coordination problems: (1) reputation (low cost information about other agents needed), (2) retaliation (frequent or long-lasting interactions needed), (3) segmentation (non-random pairing of social agents), and (4) parochialism (limited migration among groups required). The latter two imply spatial disaggregation of the analysis as a special type of what the authors call "structured populations". At a general level, group selection can be seen as the outcome of a spatial game characterized by local interactions, in which groups emerge as (to some extent) spatially isolated units. This model favors the emergence of unique local equilibria causing group diversity at the global scale. In this context the common typology of speciation - the emergence of a new species - is clarifying: allopatric speciation denotes the case in which one species splits into two species due to (spatial) separation; sympatric speciation occurs without spatial isolation (difficult because of interbreeding); peripatric speciation occurs in meta-populations at the edge of (large) populations living in vast areas; and parapatric speciation occurs in continuous populations living in vast areas where subpopulations are subject to different selection environments. All these types of speciation require group formation (starting with meta-populations), in different ways.

Van Veelen and Hopfensitz (2007) suggest that the most important distinction between group selection models of altruism is in fact between "standard models" in which assortative group formation is the key to group selection, and models in which the interest or fate of group 
members is aligned or shared. The first type of model is close to kin selection models, since here assortment is due to kin relatedness. Assortment causes altruists to interact relatively much with other altruists, giving a selective advantage. Assortment requires a propagule pool structure. The main (or perhaps only) example of the second type of model is group conflict, as the fate of individuals in winning or loosing groups are perfectly aligned. Assortment is not required here, and group selection due to group conflict might even leave an impact with a migrant pool structure (i.e. random remixing of groups in each period). Although the proposed distinction might not serve as a disjunct classification (as the group selection types are complementary rather than exclusive) it touches upon key factors and processes (and possibly even necessary conditions) underlying group selection (see also van Veelen, 2008). In particular, it clears up some confusion about kin selection versus group selection: kin selection is a special case of the first type of model, but it has no relation to the second. It is not unlikely that groups are generally more competitive and prone to conflict than individuals, because of a sharp in/outgroup distinction (parochialism).

The distinction between group selection by assortment and shared fate bears a relation with Boyd and Richerson's (1990) discussion of multiple stable equilibria (MSE). The 'shared fate model' is just one way to get MSE. Boyd and Richerson show that in systems with evolution of social behavior that have more than one evolutionarily stable strategy (such as coordination, reciprocity and sexual selection games) selection among groups can cause the spread of the strategy that is most likely to contribute to the formation of new groups. A condition for this is that processes increasing the frequency of successful strategies within groups, like behavioral variation through cultural acquiring, need to be strong relative to intergroup migration. Henrich and Boyd (2001) show that inclusion of competing, realistic strategies of cultural transmission (namely, copying the most successful individual and copying the most frequent behavior) in a cooperative dilemma generates a MSE problem at the multi-group level. Cultural group selection acting upon this can generate a unique equilibrium for the population.

Avilés (2002) introduces a new element into the group selection literature. She distinguishes between cooperation (or altruism) and "groupishness". This allows her to trace the 'coevolution' of the two characteristics of individuals. Groupishness is taken to mean that individuals are prone to join larger groups. In addition, it is assumed that group size influences the fitness of individuals. A main finding is that freeloaders - groupish non-cooperators or free riders - increase in frequency in the population if they are rare, but are selected against beyond a threshold frequency because of a reduced productivity of the groups that host them. The result is periodic cycles in the population composition. Related to this is the recent work on "identity economics." Akerlof and Kranton (2000) use a utility maximizing model to examine the psychological basis of self identity. Davis (2007) provides a convincing critique of this model from the point of view of social psychology. He argues that treating identity merely as an 
argument in a neoclassical utility function does not address the question of how social identities are related.

Finally, group selection is more effective in the presence of non-additive (genetic) interaction between individuals (in a group) or non-linear cultural interaction between individuals (institutions) (Goodnight and Stevens, 1997). This may take various forms, such as genetic interaction within (epistasis) or between individuals. Cultural interactions may occur between individuals or within an individual, when the synthesis of different cultural elements (culturgens, memes) determines the cultural fitness of that individual. ${ }^{9}$ Such cultural interaction can result in an increase in group differences, a necessary basis for group selection to work upon. Unlike additive interaction (or independence of individuals), non-additive (or non-linear) interaction allows for a larger effect of group selection compared to individual selection. The reason is that the latter type of interaction means that there will be less similarity between individuals in different generations (parent and offspring). Individual-level selection then typically will be weaker. Moreover, group selection can influence or control the interactions between individuals, since it operates at the higher level which includes the interactions, so it can select among these. Individual selection cannot do this by definition, as it works at the level below the group (i.e. the level of individual interactions). It is worth noting that many of the traditional writings on group selection - including those using simple models - neglect gene interaction and focus only on single genes or assume additive gene effects. Despite its empirical relevance, this issue seems not to have received sufficient attention in discussions of cultural group selection.

We have presented many mechanisms and factors that may influence the feasibility and effectiveness of group selection. By way of summary, Table 1 contains some of the insights about group selection mechanisms, which may be inspiring to economic applications.

\section{[INSERT TABLE 1 HERE]}

\section{Cultural group selection}

Although the foregoing section was not restricted to group selection in biological species, it is useful to consider group selection in relation to human social groups in more detail and identify distinctive mechanisms and factors. Cultural group selection pertains to socio-economic human systems, without any specific direct role played by genetic diversity and associated mechanisms,

\footnotetext{
${ }^{9}$ This aspect of interaction of genes or individuals has been generalized through the notion of social heterosis. This means that synergetic effects or fitness benefits arise in groups as a result of interactions between genetically diverse individuals (Nonacs and Kapheim, 2007). In particular, groups can include phenotypic expressions through multiple individuals that cannot be combined in single individuals. This suggests a functionality of groups that is not simply the sum of the individuals. From an economic perspective, one could interpret this as complementary specialization or labor division, which may work to the benefit of all group members.
} 
but instead cultural evolution being driven by structural cultural variants and transmission mechanisms. The evolution of group-unique social norms reinforced by systems of rewards and punishment, prestige-based and conformist imitation, and assortative interaction (group formation) are important elements of cultural group selection. Next to historical genetic and cultural group selection being responsible for current features of human society, it is likely that cultural group selection affects socio-economic changes in our time.

Group selection acting upon humans operates according to two broad categories of mechanisms, namely differential population growth of groups (genetic group selection) and cultural transmission (cultural group selection). For example, the historical diffusion of early agriculture may be attributed to both general mechanisms, where the relative contribution of each may have varied over time. Of course, cultural transmission and differential population growth can also join forces, as when groups merge or one group takes over another, or even interact (coevolution). In this case, some 'rearrangement' of behaviors and cultural habits will occur, for example, where one group will be dominant. Steele (1987) mentions a kind of reverse 'law' suggested by Marx, namely that conquest more often leads to adoption of the culture of the conquered than of the conqueror. Differential population growth is based on the group differences in the net effect of birth and death rates, and includes as specific mechanisms intergroup competition (successful groups replace less successful ones through multiplication), intergroup conflict (possibly with extinction), and differential population growth through reproductive success or "demographic swamping," (see Henrich, 2004).

Cultural transmission involves various mechanisms typically studied in social psychology, such as conformist and prestige-based transmission, following norms, and punishing non-conformists or norm-violators (Boyd and Richerson 1985; Richerson and Boyd, 2005). Cultural transmission based on the advanced cognitive and cooperative capabilities of humans make group selection in humans possibly more pronounced than in other animals. This is reinforced by the fact that human intelligence enhances group formation, through recognizing like-minded individuals (assorting), coordinating actions (agreeing upon rules and standards), and organizing complex labor division and institutions (language, planning, forward looking behavior). Humans have further been very effective in organizing war-like activities, thus being successful in cultural take-overs. Richerson and Boyd (2005) suggest that the propensity of humans to cooperate evolved through group selection processes. Cultural variation can more easily respond to group selection because cultural differences can be maintained even if there is substantial migration among groups (Cordes et al., 2008). The importance of interaction among cultural beliefs to cultural group selection is tested by Henrich (2007) and Boyd and Richerson (2002). Cultural group selection is likely to be or even have been more effective than its genetic counterpart (Cullen, 1995). 
Biased social transmission is a dominant category of cultural acquisition and it may be important for cultural transmission between groups as well. Individuals are predisposed to adopt certain pre-existing cultural variants, and so these will increase in frequency. Boyd and Richerson (1985) distinguish three types: (1) content (or direct) bias, where the adoption of cultural variants depends on the properties (attractiveness) of the variants (e.g., food characteristics); (2) prestige (or indirect) bias, the imitation of certain characteristics (e.g., style of dress) perceived to be associated with others regarded as attractive (e.g., fame, wealth, happiness); and (3) frequency dependent bias, where imitation of the majority is dominant. The latter is also known as conformist transmission, a sort of rapid learning strategy which Henrich (2004) distinguishes from normative conformity, a strategy to avoid punishment and reap benefits of group membership. Content bias is more effective but involves more time and costs compared to the other two mechanisms.

To understand the difference between cultural and genetic group selection, one should realize that whereas differential population growth is characteristic of both genetic and cultural group selection, horizontal (from peers) or oblique (from non-parental adults, such as teachers) transmission is typical for cultural acquiring but rare in genetic evolution. The reason is that cultural habits can be changed through imitation, so that there is no need to replace their carriers, while a change in genes requires that their carriers (vehicles) be replaced.

Cultural group selection can build on the existence of institutions, leading to competition between, and thus selection of, institutions (Gürerk et al., 2006). This can be regarded as a proximate answer to many relevant research questions. An ultimate explanation of cultural group selection requires an explanation of the emergence of these institutions, which can be founded on genetic evolution, whether based in between-individual or between-group selection. To illustrate that institutions can support cultural group selection, note the role of organization within groups, taking the form of hierarchical control, legislation, and even representatives of groups interacting (negotiating) with each other. Institutions like social norms homogenize groups, which in turn may lead to polarization in a population consisting of multiple groups with distinct social norms. This increases the diversity of groups and possibly group conflict, both of which contribute to the effectiveness of group selection. Surprisingly, the human capacity for imitation plays an important role in creating diversity. Frequency-dependent imitation or conformist transmission is an important mechanism in this process: individuals adopt a behavior that is frequently observed. If cultural habits of dominant individuals differ among groups, groups will become very different while internally rather homogeneous (Henrich, 2004). Prestige-based transmission can have the same effect in terms of causing homogeneity within groups. It means that individuals copy the behavior of an individual they regard as successful. In larger societies, network and information externalities may do the same job as conformist transmission. In the jargon of evolutionary economics they cause a path- 
dependent development towards homogeneity within and diversity among groups (Arthur, 1989).

Henrich (2004, Section 6.2) discusses two other important mechanisms: punishment of non-conformists (norm violators) and normative conformity. The difference between normative conformity and conformist transmission is a subtle one: the outcomes can be the same, but as opposed to the first the latter is based on the idea that the majority is indicative of the best choice. A relative gain (relative benefits or welfare) may be involved when the absolute cost that goes along with punishing felt by the enforcer is lower than the absolute cost of being punished felt by the victim. This is consistent with the widely documented human interest in relative payoffs and well-being (Bruni and Porta, 2005).

Various institutional mechanisms are responsible for creating group stability and replication. They can be seen as contributing to a kind of heritability at the level of groups, which enhances the effectiveness of group selection. For instance, the low direct fitness of individuals behaving altruistically is compensated by the social capacity to replicate pure altruism in subsequent generations, namely through social institutions and norms. This is reinforced by the existence of a meta-norm, the willingness to punish a person who did not enforce a particular norm (Axelrod, 1986). Norms are more stable under certain meta-norms. The fact that norms generate meta-norms can be regarded as an emergent property, or a new level in the multilevel evolutionary system of individuals, groups and group institutions and organization. Other mechanisms supporting a norm system are dominance, internalization, deterrence, social proof, membership, law and reputation. Persistent groups like religions are proof of the effectiveness of these mechanisms (Wilson, 2002).

Next to selection one can identify innovation at the level of groups. Innovation may be more rapid (difficult to compare though in terms of a concrete indicator) in groups than individuals, especially since many (meme) innovations spring from complementarity, combination and cooperation. For example, conquest of one group by another can give rise to combinations of elements of two cultures that can lead to new group institutions. Apart from this, random cultural variation can occur, as cultural transmission involves 'errors' of various kinds. In fact, the rate of culturally transmitted errors is probably much higher than that in genetic mutation. 'Institutional drift' means that in small groups, cultural and institutional mutations may have a large impact, causing the respective culture to be less stable. Note the similarity with the biological notion of genetic or molecular drift.

Once created, institutions can thus reinforce groups and support group selection effects along the line of group stability and inheritance, and between-group variation. Cultural variation can be created, maintained and enlarged through influencing offspring and immigrants from other groups. Certain groups adopt the more successful rules and habits of other groups. The intellectual capacity to learn, (re)search, understand, predict, and communicate in a 
sophisticated way is required then, which in turn require the more fundamental capacity of empathy and language. Simon $(1990,1993)$ argues that given bounded rationality the evolution of a trait like docility, being sensitive to suggestions, persuasion and information by others, was logical and inevitable, especially in children but also in adults. This contributes to the effectiveness of institutions fostering group selection.

A rare analysis of the role of institutions in a group selection context is Bowles et al. (2003). Their model allows for an analysis of the effect of two policies or institutions, namely resource sharing through a (linear) tax and a (uniform) redistribution scheme of tax revenues, and segmentation where individuals interact probabilistically with similar and other individuals (reflecting geographical organization or cultural dispositions). Numerical analyses show that these institutions can retard within-group selection against altruists.

The separation between genetic or genetic and cultural group selection does not mean that these are independent. Genetic diversity is likely to indirectly affect cultural diversity (in a non-deterministic way) while cultural evolution (whether by between-group or betweenindividual selection) affects genetic diversity of humans. Indeed, the history of human evolution arguably shows a subtle interaction between cultural and genetic evolution. The interaction between evolution through cultural transmission and differential population growth has been referred to as gene-culture coevolution and dual inheritance (Cavalli-Sforza and Feldman, 1981; Boyd and Richerson, 1985; Richerson and Boyd, 2005). Cultural traits have an impact on the survival and reproduction, or the genetic fitness of individuals, and in turn are influenced by these. For instance, certain food habits include tastes that are not easily learned but must have been selected, as they are related to toxicity. Boyd and Richerson refer to this as natural selection of cultural variants. Dual transmission can explain the enlargement of differences among groups. Cultural evolution is based on cultural acquiring or learning. Economic institutions can be regarded as a specific type of ecological niche that influences the selection of individual traits, which gives rise to a coevolution of individual behavior and institutions (Bowles, 2000; van den Bergh and Stagl, 2003). Thompson (2000) notes that niche construction by a group that enhances its survival and growth is precisely a group feature that can be selected for through a process of group selection. Finally, Laland et al. (2000, p.131) have used the term "niche construction" to denote "the capacity of organisms to modify sources of natural selection in their environment". Durham's (1991) typology of gene-culture coevolution illustrates the interaction dynamics that may involve group selection effects. One can have coevolution with one population being guided by individual-level selection and the other by group (or multilevel) selection, but it is also possible that both populations are subject to multilevel selection. The resulting combination of multilevel and coevolution leads to a system with a degree of complexity that is beyond intuitive comprehension. 
Finally, groups can change their composition and structure not only through genetic and cultural group selection but also through goal-oriented planning and control. The latter is of course an institution that itself has evolved over time, but contributes to non-evolutionary change once having come into existence. As a result, over a sufficiently long time period, cultural and economic change, whether occurring at individual or group levels, is likely to be a combination of evolution and non-evolutionary forces. In relation to this, the notion of "guided variation" (Boyd and Richerson, 1985) is relevant, denoting that humans can consciously and purposefully change their behavior, rules and norms through learning by doing (trial-and-error) and communication. This involves self-generation of alternatives.

\section{Some applications of cultural group selection in economics}

Here we outline themes in economics that can be linked to groups and group evolution. Our exposition is not meant to be complete in terms of coverage or description of specific research problems, questions and approaches, but merely to give an idea of the broad range of potentially interesting applications.

\section{The selection of organizational routines}

Nelson and Winter (1982) proposed the notion of routine as a property of an organization. A routine consists of a complex set of skilled individuals interacting simultaneously and sequentially. The interactions are crucial, and depend on earlier contacts (learning, adaptation) and organization-specific 'language'. Organizational memory cannot simply be reduced to the sum of individual memories, and neither to blueprints. No single individual, including the 'boss', possesses all the information to keep the organization running. The skills and communication experiences are not formally expressed, and the 'boss' may not even be aware of them, let alone be able to articulate them. If a routine breaks down it is not easy to restore, as it is the result of evolved cooperation, trust and mutual understanding. Therefore, organizational routines can be regarded as an emergent property of the group of individuals supporting it. The new employees are influenced to fit in the existing group so as to contribute its objectives. Changes in routines, and especially transitions from one to another routine, might be reframed as competition between, or selection of, routines seen as groups of individuals with complementary skills. The composition of a group will affect the performance of the related routine and thus affect the between-routine selection. At a higher level the competition between organizations can be seen as competition between group routines or sets of group routines in different organizations. Hodgson and Knutson (2007) stress the importance of group cohesion as a condition for group selection to occur, whether in the case of selecting "routines" or "social positions." Transferring ideas from group selection theory and models to this area might lead to new conceptualizations, insights and formal models, with possibly a better understanding of 
how interactions of employees in a firm translate into firm performance, dynamics and interaction with its environment, including competition with other firms. This would imply a much-needed multi-level approach to the study of the firm. An interesting question would be how within-group selection (of employees) and between-group selection (i.e. between routines, or between firms) combine: which selection type dominates under what conditions: type and size of firm and market, presence of regulation, consumer behavior and public opinion?

Group or multilevel selection allows opening the black box of routines, and describing simultaneously the dynamics of individuals within routines, and of groups of individuals that form or generate routines. Nelson and Winter implicitly note the multilevel nature of the firm, by recognizing that routines are complex sets or groups of skilled individuals interacting simultaneously and sequentially. Admittedly, the available group selection approaches may fall short in certain respects or might require molding to become more suitable for the current context. For instance, they emphasize similar rather than complementary behaviors, while routines depend very much on labor division and specialized tasks. But the latter features are not inconsistent with group selection. It should further be noted that groups can be interactors in the process of selection of individuals (Hull, 1980) or an adapting entity themselves (Lloyd, 2005). Although application of group selection to routines may be seen to emphasize the latter role, inevitably routine (group) selection will affect selection of individuals (or their characteristics) within routines, which in turn will affect the fitness of routines. ${ }^{10}$ Such a multilevel evolutionary perspective may enrich Nelson and Winter's basic framework.

\section{The selection of institutions and organizational structures}

Whereas the previous example focused on organizational routines, organisational group selection in the economy can also give rise to changes in the frequency of certain organizational structures. Defining features are size, hierarchical structure, ownership/control separation, horizontal/vertical structure (departments, matrix) and spatial structure (geographically separated sub-units). The evolutionary approach to understanding organizations developed by Hannan and Freeman (1989) is relevant here. It employs two theories of organizational change that involve adaptation. The first, referred to as selection (population adaptation) theories, is based on the idea that variety arises mainly from new organizations. Existing organizations adopt a certain structure very early in their life and rarely change it, since they are not flexible

\footnotetext{
${ }^{10}$ Lloyd (2005) takes the literature on the levels and units of selection as a starting point to clarify group selection. She identifies four fundamental questions: (1) The interactor question: what units are being actively selected in a process of natural selection? Linked to group selection, this requires identifying the conditions under which group selection influences the evolution of individuals. (2) The replicator question: which organic entities actually meet the definition of replicator? (3) The beneficiary question: who (individual, group) benefits from multilevel evolution, in the short run (adaptations) and in the long term (ultimate beneficiary species, lineages or alleles)? (4) The manifestor-of-adaptation question: at what level(s) do adaptations occur or what is the entity (individual, group or both) that does the adapting?
} 
but rigid. As a result, major innovations in organizational structure and strategy occur early in the life cycle of firms and sectors. Adaptation occurs at the population level, which involves the founding of new organizations and the demise of old, non-adapted organisations. The second type, (individual) adaptation theories, starts from the idea that individual organizations respond and adapt to environmental changes, threats and opportunities by adapting their strategy and structure. The largest and oldest organizations therefore have superior capacity for survival (selection). Market and firm demography studies show that there is a large variation in organizational structures (Hannan and Freeman, 1989; Carroll and Hannan, 2000). Organizational evolution means a change in forms, elements and connections. In addition, it can involve reallocating resources, or even splitting off parts. This can be a useful strategy if group size becomes too large. It can be seen as a special case of group selection. More generally, groups of activities might work together and compete in this way with others. Thus selection of organizations can involve group selection. In addition, selection among routines in separate organizations might receive attention, which connects with the previously discussed theme.

Somewhat in the spirit of Hayek (1976), the evolution of institutions can also be understood as resulting from group competition (Gürerk et al, 2005), although the traditional evolutionary focus is on individual-level processes (Hodgson, 2004). If institutions are strongly connected to specific groups, then dominance or convergence of institutions may result from competition between those groups. This is an alternative to the dominant view in economics to regard institutions as the result of purposeful planning and policy making. Diffusion and disappearance of institutions due to group selection is an idea especially relevant to understand social-economic history. Indeed, the latter can be characterized by local economies and groups competing for scarce space, resources, market demand, and political power. An application of particular group selection assumptions, extended with insights from institutional economics on the emergence and intrinsic dynamics of institutions (van den Bergh and Stagl, 2003), may clarify features of, and changes in, economic institutions. Other lines of research might address the interaction of interest groups, the competition of political parties for members and voters, and the emergence of international institutions resulting from coalitions (such multilateral agreements on environment, trade and human rights).

\section{Public decision making and other-regarding behavior}

Mainstream economics, whether based on neoclassical economics or public choice theory, casts public institutions in a static choice framework with given input data on options and preferences. Neoclassical economics, implicitly or explicitly, aggregates all preferences into a single social welfare function, despite the fact that Arrow (1951) showed such an aggregation is impossible. Public choice theory adds more complexity and detail by allowing for multiple stakeholders, leading to game theoretical conceptualizations at the level of groups. 
Of course, it is easy to circumvent or solve Arrow's paradox. For example, one has to step outside the static model boundaries and take into account that individuals are otherregarding, communicate within groups, deliberate and influence each other, and are sensitive to group norms. This process is dynamic, not static, and it is therefore no surprise that evolutionary theories have been invoked to understand it (Wohlgemuth, 2002). Groups compete for public attention and support, which influences public choices. This suggests a role for group selection in the analysis of public decision making. However, public choice theory has not addressed the multilevel nature of this problem. Individuals interact within groups, the composition of these groups changes over time, leaders change and leadership changes as a result, having impact on coordinated efforts within and thus performance of the group. In turn, this will affect the competition between, or selection of groups - whether interest groups or political parties. A group selection perspective might better deal with the upward and downward causality that characterizes political and public decision-making systems, and thus offer a better tool for understanding political dynamics.

\section{Rationality, markets, crowding out of social norms and public policy}

The economic theory of public policy is dominated by the assumption of 'rational agents' and a strong focus on monetary incentives. Group theories convey the message that it is not just rational for humans to make decisions as social beings, but it is an essential characteristic of our species. Likewise, incentives for individual action are socially constructed and include a gamut of positive and negative enforcement mechanisms. Bowles (1998) emphasizes that group selection is moreover an important alternative to retaliation, reputation and segmentation in understanding innovation and diffusion of socially desirable traits of human behavior. Effective policies should reckon with these foundations (Fehr and Fischbacher, 2002; Gowdy, 2004).

A group perspective on the dominance of market-based economies, diffused through deliberate pleas by politicians and economists, provides a number of refreshing insights. Bowles and Gintis (2002, p.F422), in discussing the benefits of community structure, note that "communities solve problems that might otherwise appear as classic market failures or state failures: namely, insufficient provision of local public goods such as neighborhood amenities, the absence of insurance and other risk-sharing opportunities even when these would be mutually beneficial, exclusion of the poor from credit markets, and excessive and ineffective monitoring of work effort." One might add monitoring of norms and lack of anonymity that is the cause of so much urban crime. This is consistent with a statement by K.J. Arrow (cited in Bowles and Gintis, 2002): "norms of social behaviour ... (may be) ... reactions of society to compensate for market failures". Indeed, perhaps social behaviour should be better exploited by public policies. Examples are promoting desired behaviour by offering rewards (creating status) and widely diffusing information about exemplatory cases and individuals, for instance, 
regarding successful energy conservation by households or energy innovation by firms in the face of risks posed by climate change (Nannen and van den Bergh, 2009).

An issue which also deserves attention here is the crowding out of certain types of socially desirable behaviour by individuals (social or group norms) by monetization of values in markets and specific legislation (Fehr, 2002; Frey, 1997; Frey and Oberholtzer-Gee, 1997; Polanyi, 1944; Vatn and Bromley, 1994; Vohs et al., 2006). Such crowding out is more effective in markets characterized by ephemeral and anonymous (as opposed to durable and personal) interactions between economic agents and by low entry and exit costs. According to Bowles $(2008,1605)$ the unintended effects of economic incentives "occur because people act not only to acquire economic goods and services but also to constitute themselves as dignified autonomous and moral individuals." Economic incentives can undermine group selected norms that promote the social good.

\section{Group selection and common pool dilemmas}

Various communities around the world are involved in what has been called self-organization in the context of common pool dilemmas (Ostrom, 1990). So far, no group selection argument has been used in this literature, although the evolution of institutions has received ample attention in the context of common-pool resources (Noailly et al., 2007, 2009; Sethi and Somanathan, 1996). A central question is whether resource conflicts and overuse should be addressed by strict policies set by higher-level governments, or instead by relying on the endogenous formation of use regimes. Case study research and evolutionary reasoning show that externally imposed rules and monitoring can destabilize cooperation (Ostrom, 2000). Under imperfect monitoring, external regulation may be undesirable as it will be ineffective and even harm the self-organisation process underlying the emergence of norms. With the presence of groups, selforganization may becomes more effective, as multiple experiments are done in different groups, and the most successful one can spread to the other groups - a form of group selection. Boyd and Richerson's (1990) finding (see section 5) suggests that in the case of a problem characterized by multiple stable equilibria (MSE) group selection may act as an equilibrium selection mechanism. On the negative side, groups competition might be fiercer than competition among individuals, with possibly negative consequences for resource sustainability. These are interesting issues for research, which could involves studying the role of group size, within-group heterogeneity and hierarchy, conformism or imitation, social norms, punishment, and the effect of external regulation on multilevel selection. Further, the effect of the type of interactions between individuals and groups might be examined, such as downstream effects (unidirectional), extended (complex) networks and merely neighboring contacts. 


\section{Group selection and socioeconomic power}

'Power' is a central idea in other social sciences, but it is almost completely lacking in economics. The important exception is market power, the ability to deliberately influence prices. However, in general the notion of power lacks a convincing theoretical framework. An important reason is that mainstream economics relies on the notion of representative agent, and so ignores groups and related power issues. In line with this, there is no agreement on definitions and indicators of power in the literature (Herrmann-Pillath, 2004). Possibly, the most important theory in economics that bears a direct relation to power is principal-agent theory (Jensen and Meckling, 1976). It describes a principal and an agent with different objectives and information sets, which is a cause of moral hazard. Things get more complex if it is recognized that firms function on the basis of interactions between groups (as suggested in relation to the foregoing themes 'routines' and 'organizations'). In fact, some of the complications have already been studied, using multiple agents and principals (Dosi et al., 2003). However, these frameworks still neglect the specific features of groups.

Since power is scarce (a kind of zero-sum game) it is economically relevant in multiple ways. Moreover, recognizing that power involves control over, or influence on, groups, means that a setting of multiple groups and their interactions offers a potentially useful starting point for a general conceptualization, formalization and analysis of power. Power can further be linked to historical contingencies, vested interests and positive feedback operating through increasing returns to scale, which suggests the relevance of the evolutionary notions of pathdependence and lock-in.

Power also plays a role at the level of politics and public policy. In the context of complex public issues, often multiple groups emerge around specific (vested) interests. Relevant groups considered in public choice theories are politicians, public officers ('bureaucrats'), firms, ngo's and consumers. However, the specific group features of each of these are not addressed.. Such interest groups can be regarded as the result of assortment, leading to quite homogeneous groups and sometimes polarization or large variety and even conflict at the group level. Polarization is a clear phenomenon in politics. Group selection is capable of describing the strategic and unintended interactions between the various groups and the formation and role of power.

Finally, in a modern society, groups compete for the attention and (financial) support of individuals. This involves advertisement and strategic information provision. Using group selection theory to study power realized through such means may deliver interesting insights about the impact of information provision and lessons for regulating advertisement. For a more complete and systematic discussion of power in relation to group selection see Safarzynska and van den Bergh (2009). 


\section{Summary and conclusions}

The above discussion highlights the richness of evolutionary thinking about groups and group dynamics. Such thinking implies a multilevel analytical approach, comprised of individuals and groups as well as the interactions among them. Humans possess a large capacity for otherregarding behavior, sophisticated communication, cultural transmission and social organization, as well as a tendency to behave in a parochial manner. All these contribute to the effectiveness of group selection processes. Humans show cooperation and altruism in much larger groups than most other mammals, further supporting the potential relevance of group selection for understanding human behavior.

Genetic group selection is now regarded as theoretically feasible, and it is supported by a large number of experimental and empirical studies. Cultural group selection is more controversial but potentially more relevant for human societies, since cultural evolution operates over shorter time spans. Cultural and genetic evolution, both at individual and group levels, may interact, leading to gene-culture coevolution. Cultural group selection is a process in which horizontal cultural transmission dominates - as opposed to (predominantly vertical) genetic transmission in genetic group selection. Whereas genetic transmission normally requires replacement of the carrier of the gene(s), cultural transmission can work in two ways: imitation of others, and replacement of individual carriers of cultural habits. Simplifying a bit, one can further distinguish between kin, reciprocal, and group selection, and say that kin selection is relevant to family groups, reciprocity to medium-sized groups where everyone knows each other, and cultural group selection comes into play in larger groups. ${ }^{11}$

Economists can learn much from the group selection literature, recognizing that care must be taken when transferring ideas and concepts from one discipline to another. We have sketched some possible applications of group selection and posed some research questions within the field of economics. A consequence of describing economic systems at both individual and group levels is that upward and downward causation are combined, leading to a 'multilevel economics' rather than a "microfoundations" approach (only upward causation). Evolutionary thinking has become an accepted approach in economics - witness the regular appearance of evolutionary game theory in mainstream economics journals. But the overemphasis on parsimony in modeling and analysis by focusing on one (between individuals) selection level, is unnecessarily restrictive. A structurally complete evolutionary model needs to reckon with the possibility of group selection effects.

\footnotetext{
${ }^{11}$ Koopmans (2006) adds the notions of group and missionary altruism. Group altruism reflects the effects of genetic and cultural group selection, while missionary altruism denotes the case where altruism increases the benefactor's receptiveness to the (often unintended) cultural message of the donor. Koopmans (p. 17) explains the cultural success of the missionary strategy as: "the missionary is an emblem of success and as such he is a virulent source of contagion for cultural imitation - from the pipe that he smokes to the God that he worships." Henrich and Boyd (1998) capture this phenomenon under the more general notion of 'biased cultural transmission'.
} 
We reviewed the main mechanisms of genetic and cultural group selection and how group selection might function in economic settings. We discussed the role of migrant pool versus propagule, non-random assortment, spatial population structures, institutions, group conflict, groupishness, and non-additive (genetic or behavioral) interaction between individuals. Some of these factors have received more attention in modeling than others, while no model captures all of them. An unsolved problem is how to empirically or experimentally distinguish between them.

Current group selection models have mainly addressed altruism (mostly in PD games) and the evolution of biased sex-ratios. We argue that these do not exhaust the range of possible alternative evolutionary settings. Empirical and experimental studies suggest that group selection can foster survival strategies beyond the limitations of between-individual selection. Group selection requires interdependent individual entities, such as non-additive genetic or cultural interaction or other-regarding behavior - not just altruistic actions but also envy, statusseeking or any other social interaction. Finally, group selection effects may be dominated by other types of effects, such as repeated game types of phenomena (reciprocity, and indirect reputation and reputation) and costly punishment. However, when repeated games do not well describe the evolutionary problem at hand, it should be recognized that the latter solution, costly punishment, creates a second-order free rider problem. This in turn requires invoking explanations like conformism, signaling, meta-norms and group-selection.

In this paper we indicated a range of themes and research questions that might benefit from invoking (cultural) group selection thinking. In particular, we mentioned the selection of organizational routines, the selection of organizational structures, the crowding out of group norms by markets, design of regulation and legislation, the role of group selection in common pool dilemmas, using group selection to better understand the notion of socioeconomic power, and the evolution of institutions through group competition. In applying group selection to socio-economic phenomena, specific problems will have to be addressed. For example, what does the simultaneous participation of individuals in modern societies in multiple, overlapping groups imply for the effectiveness of group selection? And how important is conflict versus assortment? In addition, existing concepts and insights regarding the functions, composition and formation of groups from economics, sociology and social psychology may have to be included to increase the relevance of applications of group selection theories to economics. This may ultimately lead to a multilevel approach to economic evolution. 


\section{References}

Akerlof, G., 2007. The missing motivation in macroeconomics. American Economic Review 97, 5-36.

Akerlof, G., Kranton, R., 2000. Economics and identity. Quarterly Journal of Economics 115, 277-317.

Alexander, R., 1987. The Biology of Moral Systems. New York: Aldine de Gruyter.

Arrow, K., 1951. Social Choice and Individual Values. New York: John Wiley.

Arthur, B., 1989. Competing technologies, increasing returns, and lock-in by historical events. Economic Journal 99, 116-131.

Avilés, L., 2002. Solving the freeloaders paradox: Genetic associations and frequencydependent selection in the evolution of cooperation among nonrelatives. Proceedings of the National Academy of Sciences 99, 14268-14273.

Avilés, L., Fletcher, J., Cutter, C., 2004. The kin composition of social groups: Trading group size for degree of altruism. American Naturalist 164,132-144.

Axelrod, R., 1986. An evolutionary approach to norms. American Political Science Review 80, 222-238.

Bergstrom, T., 2002. Evolution of social behavior: Individual and group selection. Journal of Economic Perspectives 16(2), 67-88.

Bergstrom, T., 2003. The algebra of assortative encounters and the evolution of cooperation. International Game Theory Review 5, 211-228.

Bergstrom, T., Stark, O., 2003. How altruism can prevail in an evolutionary environment. American Economic Review 83, 149-155.

Bornstein, G., Ben-Yossef, M., 1994. Cooperation in intergroup and single group social dilemmas. Journal of Experimental Social Psychology 30, 52-67.

Bowles, S., 1998. Endogenous preferences: The cultural consequences of markets and other economic institutions. Journal of Economic Literature 36, 75-111.

Bowles, S., 2000. Economic institutions as ecological niches. Behavioral and Brain Sciences 23, 148-149.

Bowles, S., 2008. Policies designed for self-interested citizens may undermine "the moral sentiments": Evidence from economic experiments. Science 320, 1605-1609.

Bowles, S., Gintis, H., 1998. The moral economy of communities: Structured populations and the evolution of pro-social norms. Evolution and Human Behavior 19, 3-25.

Bowles, S., Gintis, H., 2002. Social capital and community governance. Economic Journal, 112, F419-436.

Bowles, S.,. Choi, J.-K , Hopfensitz, A., 2003. The co-evolution of individual behaviors and social institutions. Journal of Theoretical Biology 223, 135-147. 
Boyd, R., Richerson, P., 1985. Culture and the Evolutionary Process. Chicago: University of Chicago Press.

Boyd R., Richerson, P., 1990. Group selection among alternative evolutionarily stable strategies. Journal of Theoretical Biology 145, 331-342.

Boyd, R., Richerson, P., 2002. Group beneficial norms can spread rapidly in a structured population. Journal of Theoretical Biology 215, 287-296.

Boyd, R., Gintis, H., Bowles, S., Richerson, P., 2003. The evolution of altruistic punishment. Proceedings of the National Academy of Science 100, 3531-3535.

Bruni, L.,. Porta, P., (Eds.) 2005. Economics \& Happiness: Framing the Analysis. Oxford: Oxford University Press.

Carroll, G., Hannan, M.,2000. The Demography of Corporations and Industries. Princeton: Princeton University Press.

Cavalli-Sforza, L., Feldman, W., 1981. Cultural Transmission and Evolution. Princeton: Princeton University Press.

Choi, J.-K., Bowles, S., 2007. The coevolution of parochial altruism and war. Science 318, 636640.

Colwell, R., 1981. Group selection is implicated in the evolution of female-biased sex ratios. Nature 290, 401-404.

Cordes, C. Richerson, P., McElreath, R., Strimling, P., 2008. A naturalistic approach to the theory of the firm: The role of cooperation and cultural evolution. Journal of Economic Behavior and Organization, 68(1), 125-139.

Crow, J.F., 1955. General theory of population genetics: Synthesis. Cold Spring Harbor Symposium on Quantitative Biology, 20, 54-59.

Crow, J., 2004. Cultural group selection, coevolutionary processes and large-scale cooperation, Comment on Henrich. Journal of Economic Behavior and Organization 53, 53-56.

Cullen, B., 1995. On cultural group selection. Current Anthropology 36, 819-820.

Davis, J., 2007. Akerlof and Kranton on identity in economics: Inverting the analysis. Cambridge Journal of Economics 31, 349-362.

Dawkins, R., 1976. The Selfish Gene. Oxford: Oxford University Press.

de Waal, F., 1996. Good Natured: The Origins of Right and Wrong and Other Animals. Cambridge: Harvard University Press.

de Waal, F., 2006. Primates and Philosophers: How Morality Evolved. Princeton: Princeton University Press.

Dosi, G., Levinthal, A., Marengo, L., 2003. Bridging contested terrain: Linking incentive-based and learning perspectives on organizational evolution. Industrial and Corporate Change 122, 413-436. 
Durham, W., 1991. Coevolution: Genes, Culture and Human Diversity. Stanford: Stanford University Press.

Eshel, I., Samuelson, L., Shaked, A., 1998. Altruists, egoists and hooligans in a local interaction model. American Economic Review 88, 157-179.

Eshel, I., Samuelson, L., Shaked, A., 1999. The emergence of kinship behavior in structured populations of unrelated individuals. International Journal of Game Theory 28, 447-463.

Fehr, E, 2002. Psychological foundations of incentives. European Economic Review 46, 687724.

Fehr, E., Fischbacher, U., 2002. Why social preferences matter - the impact of non-selfish motives on competition, cooperation and incentives. Economic Journal 112, C1-C33.

Fehr, E., Gächter, S., 2002. Altruistic punishment in humans. Nature 415, 137-140.

Field, A., 2001. Altruistically Inclined? Ann Arbor: University of Michigan Press.

Field, A., 2003a. Group selection and economic theory. March 2003. Working paper, Department of Economics, Santa Clara University, Santa Clara, CA.

Field, A., 2003b. Group selection and randomness; comment to Bergstrom. Journal of Economic Perspectives 17(2), 210.

Field, A., 2008. Why multilevel selection matters. Journal of Bioeconomics, 10(3), 203-238.

Forsyth, D., 2006. Group Dynamics. $4^{\text {th }}$ Ed. Belmont, CA: Thomson Wadsworth.

Foster, K., Wenseleers, T., Ratnieks, F., 2005. Kin selection is the key to altruism. Trends in Ecology and Evolution 21, 57-60.

Frank, S., 1986. Hierarchical selection theory and sex ratios. I. general solutions for structured populations. Theoretical Population Biology 29, 312-342.

Frank, S., 1997. The Price equation, Fisher's fundamental theorem, kin selection, and causal analysis. Evolution 51, 1712-1729.

Frank, S., 1998. Foundations of Social Evolution. Princeton: Princeton University Press.

Frey, B., 1997. A constitution of knaves crowds out civic virtues. Economic Journal 107, 10431053.

Frey, B., Oberholtzer-Gee, F., 1997. The cost of price incentives: An empirical analysis of motivation crowding out. American Economic Review 87, 746-755.

Garcia, J., van den Bergh, J. C. J. M., 2007. A survey of formal models of group selection. Working paper, Faculty of Economics and Business Administration, Free University, Amsterdam.

Garcia, J., van den Bergh, J.C.J.M., 2008. Evolution of parochialism by multilevel selection. Working paper, Faculty of Economics and Business Administration, Free University, Amsterdam.

Gintis, H., 2000. Game Theory Evolving. Princeton: Princeton University Press. 
Gintis, H., 2007. A framework for the unification of the behavioral sciences. Behavior and Brain Science 30, 1-16. (with commentaries)

Goodnight, C., 1990a. Experimental studies of community evolution. I. The response to selection at the community level. Evolution 44, 1614-1624.

Goodnight, C., 1990b. Experimental studies of community evolution. II. The ecological basis of the response to community selection. Evolution 44, 1625-1636.

Goodnight, C., 2000. Heritability at the ecosystem level. Proceedings of the National Academy of Science 97, 9365-9366.

Goodnight, C., Stevens, L., 1997. Experimental studies of group selection: What do they tell us about group selection in nature? The American Naturalist 150(suppl), S59-S79.

Gowdy, J., 2004. Altruism, evolution, and welfare economics. Comment on Henrich. Journal of Economic Behavior and Organization 53, 69-73.

Grafen, A., 1984. Natural selection, kin selection and group selection. In: Krebs, J., Davies, N., (Eds.). Behavioural Ecology, 2nd edition, Oxford: Blackwell, 62-84.

Grafen, A., 2007. Detecting kin selection at work using inclusive fitness. Proceedings of the Royal Society (London) B 274, 713-719.

Griffin, A., West, S., 2002. Kin selection: Fact and fiction. Trends in Ecology and Evolution 17, 15-21.

Gürerk, O., Irlenbusch, B., Rockenbach, B., 2006. The competitive advantage of sanctioning institutions. Science 312, 108.

Hamilton, W., 1964. The genetical evolution of social behavior, I and II. Journal of Theoretical Biology 7, 1-52.

Hamilton, W., 1975. Innate social aptitudes of man: An approach from evolutionary genetics. In: Fox, R. (Ed.). Biosocial Anthropology. London: Malaby Press, 133-153.

Hannan, M., Freeman, J., 1977. The population ecology of organizations. American Journal of Sociology 83, 929-84.

Hannan, M., Freeman, J., 1989. Organizational Ecology. Cambridge: Harvard University Press.

Hayek, F., 1976. Law, Legislation and Liberty, vol. 3, The Political Order of a Free People. London: Routledge.

Henrich, J., 2004. Cultural group selection, coevolutionary processes and large-scale cooperation. Journal of Economic Behavior and Organization 53, 3-35.

Henrich, J., 2007. The evolution of costly displays, cooperation, and religion. Papers on Economics and Evolution \#0721, Max Planck Institute of Economics, Jena, Germany

Henrich, J., Boyd, R., 1998. The evolution of conformist transmission and the emergence of between group differences. Evolution and Human Behavior 19, 215-242. 
Henrich, J., Boyd, R., 2001. Why people punish defectors: Weak conformist transmission can stabilize costly enforcement of norms in cooperative dilemmas. Journal of Theoretical Biology 208, 79-89.

Henrich, N., Henrich, J., 2007. Why Humans Cooperate. Oxford and New York: Oxford University Press.

Henrich, J., McElreath, R., Barr, A., Ensimger, J., Barrett, C., Bolyanatz, A., Cardenas, J., Gurven, M., Gwako, E., Henrich, N., Lesorogol, C., Marlowe, F., Tracer, D., Ziker, J., 2006. Costly punishment across human societies, Science 312, 1767- 1770.

Herrmann-Pillath, C., 2004. On power as a unifying concept in a naturalistic foundation of the social sciences. Paper presented at the Workshop on Evolutionary Concepts in Economics and Biology, Max Planck Institute for Research into Economic Systems, Jena, December 24, 2004.

Hodgson, G., 2004. The Evolution of Institutions. London: Routledge.

Hodgson, G., Knutson, T., 2007. From group selection to organizational interactors. Papers on Economics and Evolution \#0716, Max Planck Institute of Economics, Jena, Germany.

Hull, D.L., 1980. Individuality and selection. Annual Review of Ecology and Systematics 11, 311-332.

Iannaccone, L., 1999. Economics of religion. Journal of Economic Literature 36, 1465-1496.

Jensen, M., Meckling, W., 1976. Theory of the firm: Managerial behaviour, agency costs and ownership structure. Journal of Financial Economics 3, 305-360.

Koopmans, R., 2006. The mystery of neighbourly love: A cultural-evolutionary approach. Paper prepared for the panel "Evolutionary Approaches to Rationality", 16th ISA World Congress of Sociology, Durban, South Africa, 23-29 July 2006.

Laland, K., Odling-Smee, J., Feldman, W., 2000. Niche construction, biological evolution, and cultural change. Behavioral and Brain Sciences 23, 131-175.

Landa, J.T., 2008. The bioeconomics of homogeneous middleman groups as adaptive units: Theory and empirical evidence viewed from a group selection framework. Journal of Bioeconomics, 10, 259-278.

Lehmann, L., Keller, L., West, S., Roze, D., 2007. Group selection and kin selection: Two concepts but one process. Proceedings of the National Academy of Science 104, 6736-39.

Lloyd, E., 2005. Units and levels of selection. Stanford Encyclopedia of Philosophy. Published on 22 August 2005. http://plato.stanford.edu/entries/selection-units/\#3.1.

MacArthur, R., Wilson, E.O., 1967. The Theory of Island Biogeography. Princeton: Princeton University.

Maynard Smith, J., 1964. Group selection and kin selection. Nature 201, 1145-1146.

Melis, A., Hare, B., Tomasello, M., 2006. Chimpanzees recruit the best colaborators. Science $311,1297-1300$. 
Muir, W., 1996. Group selection for adaptation to multiple-hen cages: Selection program and direct responses. Journal of Poultry Science 75, 447-458.

Nannen, V., van den Bergh, J.C.J.M., 2009. Policy instruments for evolution of bounded rationality: Application to climate-energy problems. MPRA Paper 13818, University Library of Munich, Germany, http://mpra.ub.uni-muenchen.de/13818.

Nelson, R., Winter, S., 1982. An Evolutionary Theory of Economic Change. Cambridge, MA: Belknap Press.

Noailly, J., Withagen, C., van den Bergh, J.C.J.M., 2007. Evolution of social norms in a common-pool resource game. Environmental and Resource Economics 36, 113-141.

Noailly, J., van den Bergh, J.C.J.M., Withagen, C., 2009. Local and global interactions in an evolutionary resource game. Computational Economics, 33(2), 155-173.

Nonacs, P., Kapheim, K., 2007. Social heterosis and the maintenance of genetic diversity. Journal of Evolutionary Biology 20, 2253-2265.

North, D., 1981. Structure and Change in Economic History. New York: W.W. Norton.

North, D., 1997. Institutions. Journal of Economic Perspectives 5, 97-112.

Nowak, M., Sigmund, K., 2000. Games on grids. In: Dieckmann, U., Law, R., Metz, J., (Eds.). The Geometry of Ecological Interactions. Cambridge, UK: Cambridge University Press, 135-150.

Nowak, M., Sigmund, K., 2005. Evolution of indirect reciprocity. Nature 437, 1291-1298.

Ohtsuki H., Hauert, C., Lieberman, E., Nowak, M., 2006. A simple rule for the evolution of cooperation on graphs and social networks. Nature 441, 502-505.

Ostrom, E., 1990. Governing the Commons: The Evolution of Institutions for Collective Action. Cambridge, UK: Cambridge University Press.

Ostrom, E., 2000. Collective action and the evolution of social norms. Journal of Economic Perspectives 14(3), 137-158.

Panchanthan, K., Boyd, R., 2005. Indirect reciprocity can stabilize cooperation without the second-order free rider problem. Nature 432, 499-502.

Pepper, J., Smuts, B., 2000. The evolution of cooperation in an ecological context: An agentbased model. In: Kohler, T., Gumerman, G., Dynamics in Human and Primate Societies. Oxford: Oxford University Press, pp. 45-76.

Pepper, J., Smuts, B., 2002. A mechanism for the evolution of altruism among non-kin: positive assortment through environmental feedback. American Naturalist 160, 205-212 .

Polanyi, K., 1944. The Great Transformation. Boston: Beacon Press.

Potts, J., 2000. The New Evolutionary Microeconomics: Complexity, Competence, and Adaptive Behavior. Cheltenham, UK: Edward Elgar.

Price, G., 1970. Selection and covariance. Nature 227, 520-521. 
Price, G., 1972. Extension of covariance selection mathematics. Annals of Human Genetics 35, 485-490.

Queller, D., 1992. Quantitative genetics, inclusive fitness, and group selection. The American Naturalist 139, 540-558.

Richerson, P., Boyd, R., 2005. Not By Genes Alone: How Culture Transformed Human Evolution. Chicago: The University of Chicago Press.

Robertson, A., 1966. A mathematical model of the culling process in dairy cattle. Animal Production 8, 95-108.

Robson, A., 2001. The biological basis of economic behaviour. Journal of Economic Literature 39(1), 11-33.

Robson, A., 2002. Evolution and human nature. Journal of Economic Perspectives 16(2), 89106.

Ruse, M., 1979. Sociobiology: Sense or Nonsense. Dordrecht: Reidel Publishing Company.

Safarzynska, K., van den Bergh, J.C.J.M., 2009. Evolving power and environmental policy: Explaining institutional change with group selection. Ecological Economics, forthcoming.

Samuelson, P., 1993. Altruism as a problem involving group versus individual selection in economics and biology. American Economic Review 83, 143-148.

Sethi, R., Somanathan, E., 1996. The evolution of social norms in common property resource use. American Economic Review 86, 766-788.

Silk J., Alberts, S., Altmann, J., 2003. Social bonds of female baboons enhance infant survival. Science 302, 1231-1234.

Silk, J., Brosnan, S., Vonk, J., Henrich, J., Povinelli, D., Richardson, A., Lambeth, S., Mascaro, J., and Schapiro, J., 2005. Chimpanzees are indifferent to the welfare of unrelated group members. Nature 437, 1357-1359.

Simon, H., 1990. A mechanism for social selection and successful altruism. Science 250, 16651668.

Simon, H., 1993. Altruism and economics. American Economic Review 83, 156-161.

Simpson, E., 1951., The interpretation of interaction in contingency tables. Journal of the Royal Statistical Society Series B 13, 238-241.

Slatkin, M., Wade, M., 1978. Group selection on a quantitative character. Proceedings of the National Academy of Science 75, 3531-3534.

Sober, E., 1981. Holism, individualism, and the units of selection. Proceedings of the Philosophy of Science Association 1981(2), 93-121.

Sober, E., Wilson, D., 1998. Unto Others: The Evolution and Psychology of Unselfish Behavior. Cambridge, MA: Harvard University Press.

Soltis, J., Boyd, R., Richerson, P., 1995. Can group-functional behaviors evolve by cultural group selection? Current Anthropology 36, 473-494. 
Steele, D., 1987. Hayek's theory of cultural group selection. Journal of Libertarian Studies 8, 171-195.

Swenson, W., Wilson, D., Elias, R., 2000. Artificial ecosystem selection. Proceedings of the National Academy of Science 97, 9110-9114.

Thompson, N., 2000. Niche construction and group selection. Behavioral and Brain Sciences $23,161-162$.

Traulsen A., Nowak, M., 2006. Evolution of cooperation by multilevel selection. Proceedings of the National Academy of Science 103, 10952-10955.

Trivers, R., 1971. The evolution of reciprocal altruism. Quarterly Review of Biology 46, 35-57.

van den Bergh, J.C.J.M., Gowdy, J., 2003. The microfoundations of macroeconomics: An evolutionary perspective. Cambridge Journal of Economics 27, 65-84.

van den Bergh, J.C.J.M., Stagl, S., 2003. Coevolution of economic behaviour and institutions: Towards a theory of institutional change. Journal of Evolutionary Economics 13, 289-317.

van Veelen, M., 2008. Group selection, altruism and cooperation: Shared genes or shared interests. Working paper, CREED, University of Amsterdam.

van Veelen, M., Hopfensitz, A., 2007. In love and war: altruism, norm formation, and two different types of group selection. Journal of Theoretical Biology 249, 667-680.

Vatn, A., Bromley, D., 1994. Choices without prices without apologies. Journal of Environmental Economics and Management 26, 129-148.

Vohs, K., Mead, N., Goode, M., 2006. The psychological consequences of money. Science 314, 1154-1156.

Wade, M., 1976. Group selection among laboratory populations of Tribolium. Proceedings of the National Academy of Science 73, 4604-4607.

Williams, G., 1966. Adaptation and Natural Selection. Princeton: Princeton University Press.

Wilson, D., 1975. A theory of group selection. Proceedings of the National Academy of Science 72, 143-146.

Wilson, D., 1983. The group selection controversy: History and current status. Annual Review of Ecology and Systematics 14, 159-187.

Wilson, D., 2000. The challenge of understanding complexity. Behavioral and Brain Sciences 23, 163-164.

Wilson, D., 2002. Darwin's Cathedral: Evolution, Religion, and the Nature of Society. Chicago: University of Chicago Press.

Wilson, D., 2005. Human groups as adaptive units: Toward a permanent consensus. In: Carruthers, P., Laurence, S., Stich, S., (Eds.), The Innate Mind: Culture and Cognition. New York: Oxford University Press, pp. 69-88. 
Wilson, D., Sober, E., 1994. Re-introducing group selection to the human behavioral sciences. Behavioral and Brain Sciences 17, 585-654.

Wilson, E.O. 1975. Sociobiology: The New Synthesis. Cambridge, MA: Harvard University Press.

Wilson, E.O., Hölldobler, B., 2005. Eusociality: Origin and consequences. Proceedings of the National Academy of Science 102, 13367-13371.

Wilson, D., Wilson, E.O., 2007. Rethinking the theoretical foundation of sociobiology. The Quarterly Review of Biology 82, 327-348.

Wohlgemuth, M., 2002. Evolutionary approaches to politics. Kyklos 44, 223-246.

Wynne-Edwards, V., 1962. Animal Dispersion in Relation to Social Behaviour. Edinburgh: Oliver and Boyd. 
Table 1. Factors determining the effectiveness of group selection

\begin{tabular}{|c|c|c|}
\hline Factor & Negative if present & Positive if present \\
\hline $\begin{array}{l}\text { Population structure } \\
\text { and dynamics }\end{array}$ & $\begin{array}{l}\text { Migrant pool (temporary } \\
\text { groups) } \\
\text { Migration }\end{array}$ & $\begin{array}{l}\text { Propagule pool (permanent, separate } \\
\text { groups) } \\
\text { (Non-random) assorting. } \\
\text { Endogenous splitting of groups }\end{array}$ \\
\hline Among-group diversity & $\begin{array}{l}\text { Small } \\
\text { Initially random }\end{array}$ & $\begin{array}{l}\text { Historically large } \\
\text { Initially non-random (e.g., assorting) }\end{array}$ \\
\hline Spatial structure & & $\begin{array}{l}\text { Spatial isolation } \\
\text { Local interaction } \\
\text { Spatial clustering/assorting }\end{array}$ \\
\hline Selection pressure & & $\begin{array}{l}\text { Direct interaction among groups, } \\
\text { Group conflict } \\
\text { Biased cultural transmission }\end{array}$ \\
\hline Individual interaction & $\begin{array}{l}\text { Genetic or behavioral } \\
\text { independence } \\
\quad \text { of individuals }\end{array}$ & $\begin{array}{l}\text { Non-additive (genetic) interaction } \\
\text { between individuals (in a group) and } \\
\text { cultural interaction between } \\
\text { individuals (institutions) increase } \\
\text { group differences }\end{array}$ \\
\hline Group coherence & $\begin{array}{l}\text { Weak internal group relations } \\
\text { Migrant pool }\end{array}$ & $\begin{array}{l}\text { Stable group, Propagule pool } \\
\text { Strong internal relationships } \\
\text { Group institutions (norms, punish, } \\
\quad \text { reward, sharing) } \\
\text { Unique communication/signals } \\
\text { (chemical, language, cultural habits) }\end{array}$ \\
\hline Groupishness & Groupish free riders & Assortment of groupish altruists \\
\hline Group size & $\begin{array}{l}\text { Large group size negative as it } \\
\text { hampers genetic or cultural } \\
\text { drift, and may involve costs } \\
\text { (anonymity, communication, } \\
\text { coordination, monitoring, } \\
\text { compliance) }\end{array}$ & $\begin{array}{l}\text { Large size positive if synergy of } \\
\text { (complementary) individual traits } \\
\text { (e.g., labour division) } \\
\text { Small group may allow for spatial } \\
\text { isolation and random (genetic or } \\
\text { cultural) drift }\end{array}$ \\
\hline
\end{tabular}

